\title{
Response of Soil Organic Carbon and Its Active Fractions to Restoration Measures in the Karst Rocky Desertification Ecosystem, SW China
}

\author{
Yixin Bai ${ }^{1}$, Maoyin Sheng ${ }^{1,2 *}$, Qijuan Hu${ }^{1}$, Chu Zhao ${ }^{1}$, Hailong Xiao ${ }^{1}$ \\ ${ }^{1}$ National Engineering Research Centre for Karst Rocky Desertification Control, \\ Guizhou Normal University, Guiyang 550001, China \\ ${ }^{2}$ Guizhou Engineering Laboratory for Karst Rocky Desertification Control and Derivative Industry, \\ Guiyang 550001, China
}

Received: 1 June 2020

Accepted: 27 September 2020

\begin{abstract}
Soil organic carbon (SOC) is the dynamic medium of carbon transfer and the main way of carbon circulation in karst ecosystem, SOC and soil labile organic carbon (LOC) is essential for karst soil $\mathrm{C}$ cycling. There has been very little research about the differentiation of SOC and LOC in karst ecosystem. In this study, six typical restoration measures were investigated in the karst rocky desertification ecosystem, southwest China, including: restoration with Zanthoxylum bungeanums (HJ), restoration with Hylocereus undulates (HL), restoration with Pennisetum sinese (HZ), restoration with Medicago sativa (MX), restoration with Sabina chinensis (YB), and abandoned and natural recovery (LH). The SOC contents, SOC stocks, LOC contents (water soluble organic carbon (WSOC), easily oxidizable organic carbon (EOC), particulate organic carbon (POC), light fraction organic carbon (LFOC)), and the carbon pool management index (CPMI) were investigated. The results indicated that the SOC contents, SOCS and LOC contents of the six measures were the highest in YB, followed by the LH, and the two were significantly higher than the other four measures. The soil CPMI contents of 0-20 cm layer under the different restoration measures decreased in the following order: $\mathrm{YB}>\mathrm{HJ}>\mathrm{MX}$ $>\mathrm{HL}>\mathrm{HZ}$. Correlation analysis showed that SOC was positively correlated with soil LOC $(P<0.01)$, and LOC was positively correlated with each other $(P<0.01)$. These findings suggest that restoration with Sabina chinensis, abandoned and natural recovery are more conducive to the management and protection of karst ecological environment. Restoration with Zanthoxylum bungeanums can be used as a priority economic species for karst rocky desertification and mountain agricultural development in southwest China. Soil WSOC, EOC, POC, and LFOC can be used as effective indicators to reflect SOC pools, and soil CPMI can also be used as a sensitive indicator to reflect soil management.
\end{abstract}

Keywords: karst ecosystem, restoration measures, soil organic carbon, soil labile organic carbon, carbon pool management index

*e-mail:shmoy@163.com 


\section{Introduction}

Soil is a crucial part of the terrestrial ecosystem and the carrier of many ecological processes in the ecosystem [1]. Soil carbon is a core component of the terrestrial carbon pool and an essential foundation for soil fertility. The soil carbon pool is about twice that of atmospheric and three times that of vegetation carbon pool, in which the soil organic carbon (SOC) contents accounts for more than $50 \%$ of the total soil carbon [2-4], and small changes in SOC storage will have a significant impact on atmospheric $\mathrm{CO}_{2}$ concentrations [5-8]. However, SOC content is only a result of longterm balanced mineralization of soil organic carbon, and it is difficult to respond to short-term land use changes, and it cannot well reflect the changes of soil quality and conversion rates in a short time [9-12]. Previous studies have found that soil labile organic carbon (LOC) was more sensitive to land use change than SOC [13-19]. Although it accounts for a minor part of total SOC pools, it can reflect small changes in SOC pools caused by soil management measures and environmental changes [20-24]. According to different measurement methods, soil LOC can mainly be characterized as water-soluble organic carbon (WSOC), easily oxidizable organic carbon (EOC), particulate organic carbon (POC), and light fraction organic carbon (LFOC), which can all reflect SOC availability and soil quality in different degrees [25-27]. The soil carbon pool management index (CPMI) considers SOC pools and LOC comprehensively, which can more sensitively reflect the degree of soil quality degradation or regeneration caused by various land use or management measures [28-30].

Karst refers to the geological process that is mostly carried out by the chemical dissolution action of water on water-soluble rocks (usually limestone, dolomite, or marble), and supplemented by the mechanical actions of erosion or latent erosion of flowing water and rock avalanche which is from above ground and underground landscape [31-32]. Karst landforms are distributed in soluble rock regions around the world, with a total area of approximately 510 million $\mathrm{km}^{2}$, accounting for $10 \%$ of the total area of the earth $[31,33]$. The karst area in southwest China centered on Guizhou, with an area of about 540,000 square kilometers, is one of the three largest karst areas in the world [31, 34-35]. Karst rocky desertification means that the process or result of rocky desert landscape on the surface under the fragile ecological environment of karst, which is caused by the unreasonable social and economic activities of human beings [31, 36]. Karst rocky desertification has become the most severe eco-environmental problem restricting sustainable development in Southwest China [32]. Since the 1990s, Chinese governments at all levels have launched a series of major ecological restoration projects to control rock desertification. Artificial vegetation restoration is an essential ecological management measure. Due to the different tree species and their configurations under different models, it will inevitably lead to the law, quantity, and composition of litter, as well as differences in forest land environments, which will affect the SOC pools [18, 37-39]. In recent years, studies on the impact of different rock desertification control measures on the eco-environment have mainly focused on plant community structure, soil phychemical properties, the nutrient cycling of carbon, nitrogen, and phosphorus, and the characteristics of ecological stoichiometry [18, 32, 37-42]. However, there is an unusual lack of research on SOC, LOC, and CPMI.

In this study, the typical karst rocky desertification area, Huajiang Town, Guanling County, Guizhou Province, in Southwest China was selected as the study area to investigated six typical karst rocky desertification vegetation restoration measures, i.e., (1) restoration with Zanthoxylum bungeanum (HJ), (2) restoration with Hylocereus undulates (HL), (3) restoration with Pennisetum sinese (HZ), (4) restoration with Medicago sativa (MX), (5) restoration with Sabina chinensis(YB), and (6) abandoned and natural recovery as reference (LH) and their impacts on SOC, LOC (WSOC, EOC, POC, LFOC), and CPMI. The objectives of our study were to: (1) ascertain the amounts of SOC (including contents and stocks) under different vegetation restoration measures; (2) assess the differences of characteristics of LOC and CPMI under different vegetation restoration measures; (3) reveal the relationships between SOC, LOC, CPMI, and phy-chemical indicators. Our results will provide the scientific and theoretical basis for vegetation restoration and reconstruction of karst rocky desertification control and carbon cycle management in Southwest China.

\section{Materials and Methods}

\section{Study Areas}

The study site was located on both sides of the Beipanjiang River, with a distance of $10 \mathrm{~km}$ from Huajiang Town, Anshun City of Guizhou Province, China $\left(25^{\circ} 38^{\prime} 19^{\prime \prime}-25^{\circ} 41^{\prime} 32^{\prime \prime} \mathrm{N}, 1^{\circ} 35^{\circ} 38^{\prime} 31^{\prime \prime}-106^{\circ} 40^{\prime} 51^{\prime \prime} \mathrm{E}\right)$. It is a typical karst plateau gorge with large reliefs and deep valleys. The greatest relative height is approximately $1000 \mathrm{~m}$, with an altitude ranging from $450 \mathrm{~m}$ to $1450 \mathrm{~m}$. (Fig. 1). The average annual precipitation is approximately $1100 \mathrm{~mm}$, mainly distributed in the period of May to October and accounting for $83 \%$ of the annual precipitation. The rock is mainly composed of dolomite, argillaceous dolomite, and shale of Triassic origin. The soil is mainly composed of yellow soil and yellow limestone. The vegetation is subtropical evergreen deciduous coniferous forest and broad-leaved mixed forest. Most of the original vegetation was destroyed, and now it is mainly secondary vegetation. The overall coverage of vegetation in this area is less than $3 \%$, and the rate of 


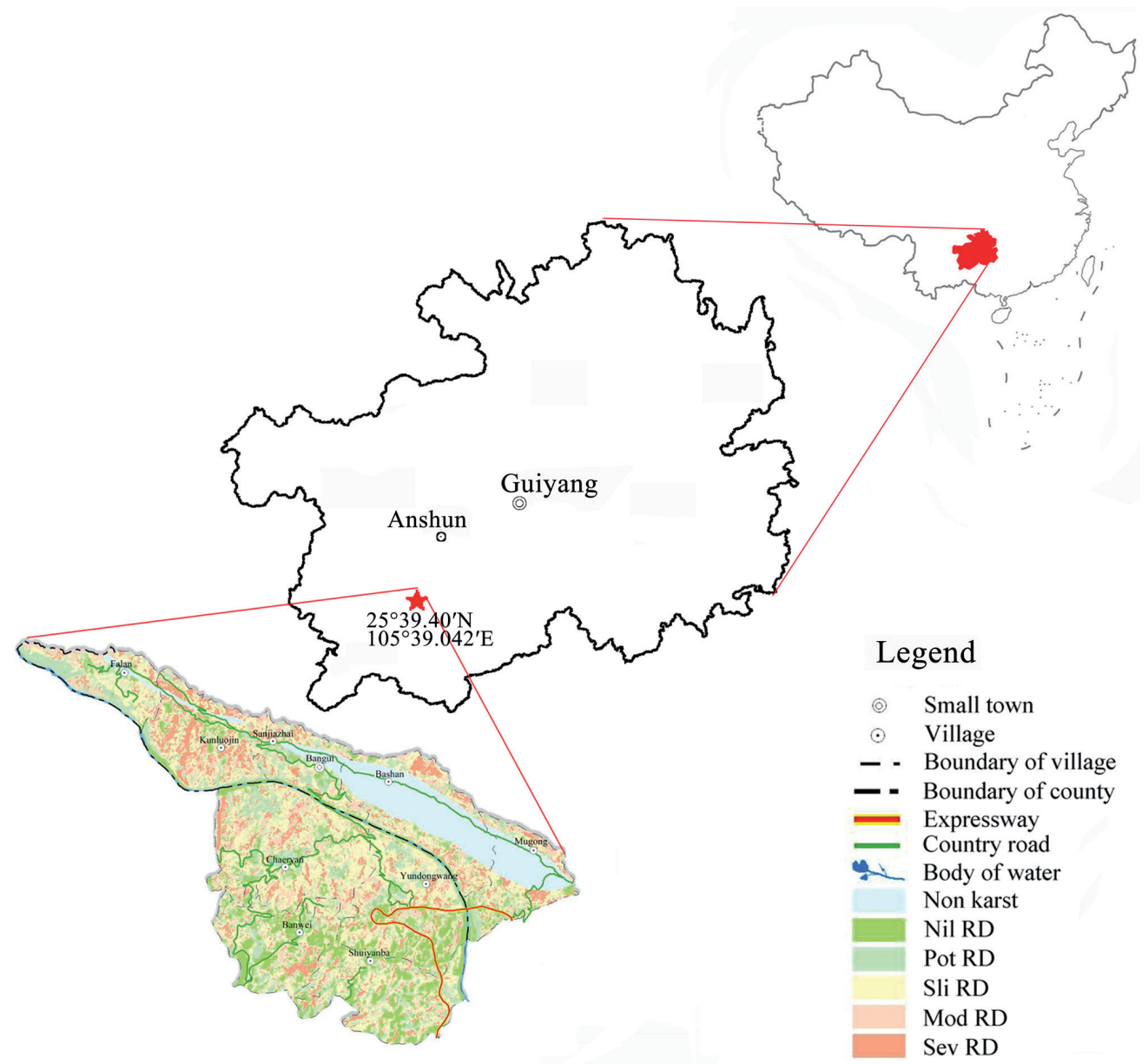

Fig. 1. Location of the study site in Huajiang Town, China.

exposed rocks is above $70 \%$. Since the 1990 s, several ecological restoration projects, such as Grain for Green and Comprehensive control of rocky desertification have been carried out. Sabina chinensis, Pinus massoniana and Toona sinensis were the main species in arbor, Zanthoxylum bungeanum was the main species in shrub, and Medicago sativa and Pennisetum sinese were the main species in grassland. The study area is a public demonstration area for rocky desertification control during the period from the Ninth Five-Year Plan to the Twelfth Five-Year Plan. The governance model, restoration, and reconstruction of vegetation have different characteristics at different time stages.

\section{Study Sites and Soil Analysis}

Soil samples were collected from six typical karst rocky desertification restoration measures (HJ, HL, HZ, MX, YB, and LH). The six study sites were in one background, which was according to local farmer interviews. Before the plots were withdrawn from cultivation, the land was cultivated land with longterm continuous cultivation history. Besides, the natural environment factors in six study sites such as mother rock, soil, altitude, slope position and aspect of the plot are similar. HJ, the recovery period is about 20 years, the average plant height is about $2.3 \mathrm{~m}$, the maximum crown diameter is about $4 \mathrm{~m}$, no fertilizer, no tillage. In addition to Zanthoxylum bungeanum there are a few herbs on the surface, such as Setaria viridis, Epimeredi indica. HL, the planting period is about 20 years, the average plant height is about $1.8 \mathrm{~m}$, one year ripe, the planting density is low, no fertilization, tillage and other measures, the surface is accompanied by a small amount of Epimeredi indica, Alopecurus aequalis, and other growth. HZ and MX, the restoration period is about 18 years, and there is no fertilization or plowing measures. YB is closed for a long time, with less human interference, the tree height is more than $7 \mathrm{~m}$, and there is no fertilization activity. LH, formed by returning cultivated land or sloping land, to a desolation age of about 20 years, without human disturbance, and shrubs has been formed. The main species are Digitaria sanguinalis, Setaria viridis, and Oplismenus compositus.

In March 2019, we established three representative $20 \times 20 \mathrm{~m}$ plots for each restoration measures, and three sampling points were selected according to the S-shaped point distribution method in each sample $[30,32]$. Before collecting soil samples, we removed the litter on the soil surface, the sampling depth is $20 \mathrm{~cm}$, and each sampling point divides the soil profile 
into three layers according to $0-5,5-10$, and $10-20 \mathrm{~cm}$. The soil bulk density of each soil layer was measured by ring cutter soil. The soil samples at each sampling point in each quadrant are mixed into a soil sample according to the soil layer, and then sealed and brought back to the laboratory. Roots, stones, and other debris were removed carefully, and the samples were sieved through a $2-\mathrm{mm}$ mesh sieve. In the laboratory, each soil was divided into two subsamples: one was stored at $4^{\circ} \mathrm{C}$ for measurement of the WSOC, the other was air-drying for determination of SOC, EOC, POC, LFOC, and other soil properties.

\section{Sample Analyses}

The determination of soil sample index is repeated three times. The soil bulk density was measured by the cutting ring method, and the $\mathrm{pH}$ values were measured by $\mathrm{pH}$ meter (solid-water ratio of 1:2.5). SOC was determined by the potassium dichromate $\left(\mathrm{K}_{2} \mathrm{Cr}_{2} \mathrm{O}_{7}\right)$ oxidation-heating method. Soil TN was assayed by the Kjeldahl digestion method. The volume of soil gravel is determined by the drainage method. After the soil bulk density is measured, the soil in the cutting ring is sieved through a $2 \mathrm{~mm}$ soil sieve, the soil particles on the surface of the gravel are washed with clean water, and dried in a measuring cup (accuracy $0.5 \mathrm{~mL}$ ). The volume of gravel is determined by the drainage method, and the volume content of soil gravel is calculated [43].

Soil WSOC was determined as described by Jones [44]. In short, $5 \mathrm{~g}$ fresh soil samples were mixed with $25 \mathrm{~mL}$ (soil-water ratio of 1:5) deionized water in centrifuge tube, shaken for $30 \mathrm{~min}$ and then centrifuged at $8000 \mathrm{rpm}$ for $10 \mathrm{~min}$. After the supernatant was filtered with 0.45 um filter membrane, the total organic $\mathrm{C}$ concentration of this sample was analyzed on the Multi N/C analyzer (Analytik Jena 3100, Germany). The soil EOC was measured using oxidation with $0.333 \mathrm{~mol} \mathrm{~L}^{-1} \mathrm{KMnO}_{4}$ [29]. Shortly, a soil sample containing about $15 \mathrm{mg}$ of $\mathrm{C}$ was added into $50 \mathrm{~mL}$ centrifuge tubes and was reacted with $25 \mathrm{~mL}$ $0.333 \mathrm{~mol} \mathrm{~L}^{-1} \mathrm{KMnO}_{4}$ for $1 \mathrm{~h}$ on a shaker, and then centrifuged at $4000 \mathrm{rpm}$ for $5 \mathrm{~min}$. After being diluted with ultrapure water, supernatant's absorbance was read at $565 \mathrm{~nm}$ spectrophotometry. The POC was separated from $2 \mathrm{~mm}$ soil following the method of Camberdella [45]. Portions $(10 \mathrm{~g})$ of air-dried soil were poured into $30 \mathrm{~mL}$ of sodium hexametaphosphate $\left(\mathrm{NaPO}_{3}\right)_{6}$ (5 $\left.\mathrm{g} \mathrm{L}^{-1}\right)$, with shaking on a reciprocating shaker for $18 \mathrm{~h}$. Pass a $53 \mu \mathrm{m}$ sieve and rinse with distilled water into an aluminum box to ensure separation. All material remaining on the box was washed into a dry dish, oven-dried at $60^{\circ} \mathrm{C}$ for $48 \mathrm{~h}$, and ground to determine the $\mathrm{C}$ content. The LFOC was measured based on density fractionation described by Janzen [46]. Briefly, $10 \mathrm{~g}$ of air-dried soil sample was added in a plastic centrifuge tube and reacted with $50 \mathrm{~mL}$ of $\mathrm{NaI}$ solution (1.7 $\left.\mathrm{g} \mathrm{cm}^{-3}\right)$. After shaking and centrifuging, the suspension with the floating particles was vacuum filtered. In the process of filtration, ultrapure water was used to rinse the remanent $\mathrm{NaI}$ on the floating particles, and then, $\mathrm{C}$ contents of the particles was analyzed.

\section{Calculation and Statistical Analysis}

In this study, SOC stocks in the soil profile were calculated based on the following equations [18, 21]:

$$
\begin{gathered}
S O C S=C \times D \times E \times(1-G) / 100 \\
G=D_{g} / D_{s}
\end{gathered}
$$

...where SOCS is the SOC stock $\left(\mathrm{kg} / \mathrm{m}^{2}\right), \mathrm{C}$ represents the SOC concentrations $(\mathrm{g} / \mathrm{kg}), \mathrm{D}$ is the soil bulk density $\left(\mathrm{g} / \mathrm{cm}^{3}\right), \mathrm{E}$ is the thickness of the soil layer $(\mathrm{cm}), \mathrm{G}$ is the volume proportion of soil and sediment $>2 \mathrm{~mm}(\%), \mathrm{D}_{\mathrm{g}}$ is the dry weight of gravel, and $\mathrm{D}_{\mathrm{s}}$ is the dry weight of total soil.

LOC/SOC in the soil profile were calculated based on the following equations [32]:

$$
F_{W}=L O C / S O C
$$

...where LOC stands for WSOC, EOC, POC, LFOC.

The Soil CPMI comprehensively considers SOC and LOC, and can more sensitively reflect the degree of soil quality degradation or regeneration caused by various land use or management measures [29-30]. Since all vegetation restoration measures are based on sloping farmland, the calculation of the soil CPMI is based on the slope farmland which is naturally restored:

$$
N L C=S O C-E O C
$$

...where NLC is Non-labile C.

$$
L=L O C / N L C
$$

...where L is Lability of C.

$$
L I=L_{s} / L_{r}
$$

...where LI is the lability index. $\mathrm{L}_{\mathrm{s}}$ and $\mathrm{L}_{\mathrm{r}}$ are the $\mathrm{C}$ lability of the sample soil and reference soil, respectively.

$$
C P I=S O C_{s} / S O C_{r}
$$

...where CPI is Carbon pool index. $\mathrm{SOC}_{\mathrm{s}}$ and $\mathrm{SOC}_{\mathrm{r}}$ are the SOC of the sample soil and reference soil, respectively.

$$
C P M I=C P I \times L I \times 100
$$

...where CPMI is Carbon pool management index.

All data collected were statistically analyzed by SPSS version 22.0 (SPSS Incorporated, USA) and given as the average \pm standard error (SE) based on 
three repeated processing. We used one-way ANOVA to examine differences of measured parameters (SOC, SOCS, WSOC, EOC, POC, LFOC, CPMI, and the ratios of $\mathrm{LOC}$ to $\mathrm{SOC}$ ) among the vegetation restoration measures, with separation of means-tested by the least significant difference method (LSD) at the 95\% confidence level. Pearson's correlation coefficients were computed to investigate the relationships between SOC, LOC, CPMI, and phy-chemical indicators.

\section{Results}

\section{Changes in SOC and SOCS under Different Restoration Measures}

The SOC contents of the six restoration measures ranged from 8.96 to $53.32 \mathrm{~g} / \mathrm{kg}$, the maximum value appeared in $0-5 \mathrm{~cm}$ of YB which was $53.32 \mathrm{~g} / \mathrm{kg}$, and the minimum value appeared in $10-20 \mathrm{~cm}$ of $\mathrm{HZ}$, which was $8.32 \mathrm{~g} / \mathrm{kg}$ (Fig. 2a). The different vegetation restoration measures and soil depths had significant effects on SOC contents. The SOC contents of different restoration measures showed the highest YB in each soil layer, followed by LH, both of which were significantly higher than the other four restoration measures. In the 0-20 cm soil layer, the changing trend of SOC contents was $\mathrm{YB}>\mathrm{LH}>\mathrm{HJ}>\mathrm{MX}>\mathrm{HL}>\mathrm{HZ}$. In the whole soil profile, the SOC contents of each measures decreased with the increase of soil depth, and each soil layer showed a significant difference. The proportion of SOC in the $0-5 \mathrm{~cm}$ layer was $38.96 \% \sim 47.23 \%$, with visible surface aggregation.

The SOCS of the six restoration measures ranged from 0.57 to $2.04 \mathrm{~kg} / \mathrm{m}^{2}$, the maximum value appeared in $0-5 \mathrm{~cm}$ layer of YB which was $2.04 \mathrm{~kg} / \mathrm{m}^{2}$, and the minimum value appeared in 10-20 cm layer of $\mathrm{HZ}$ which was $0.57 \mathrm{~kg} / \mathrm{m}^{2}$ (Fig. 2b). The SOCS of each vegetation restoration measures in the same soil layer has the same trend as the SOC contents. It also showed the highest in $\mathrm{YB}$, followed by LH and significantly greater than the other four measures. The variation trend of SOCS in different vegetation restoration measures was different among different soil layers. In the 0-5, 5-10, and $10-20 \mathrm{~cm}$ layer, the SOCS was reduced in different measures and arranged in the following order respectively: $\mathrm{YB}>\mathrm{LH}>\mathrm{MX}>\mathrm{HJ}>\mathrm{HZ}>\mathrm{HL}$, $\mathrm{YB}>\mathrm{LH}>\mathrm{HJ}>\mathrm{MX}>\mathrm{HZ}>\mathrm{HL}, \quad$ and $\mathrm{LH}>\mathrm{YB}>$ $\mathrm{HJ}>\mathrm{MX}>\mathrm{HL}>\mathrm{HZ}$. In the 0-20 $\mathrm{cm}$ layer, the SOCS under different measures decreased in the following order: $\mathrm{YB}>\mathrm{LH}>\mathrm{HJ}>\mathrm{MX}>\mathrm{HL}>\mathrm{HZ}$. In the vertical soil profile, the SOCS of all the restoration measures decreased with the increase of soil depth, and significant differences were discovered among all the soil layers except 5-10 and $10-20 \mathrm{~cm}$ of HJ. The $0-5 \mathrm{~cm}$ SOCS accounted for $35.67 \% \sim 45.28 \%$ of each measures, showing a consistent change pattern with SOC, and has obvious surface aggregation.

\section{Changes in Soil Labile Organic Carbon under Different Restoration Measures}

\section{Water-Soluble Organic Carbon}

The soil WSOC contents of the six restoration measures ranged from 59.44 to $180.29 \mathrm{mg} / \mathrm{kg}$, the maximum value occurring in $0-5 \mathrm{~cm}$ depth of $\mathrm{YB}$ which was $180.29 \mathrm{mg} / \mathrm{kg}$, and the minimum value occurring in 10-20 cm depth of HL which was $59.44 \mathrm{mg} / \mathrm{kg}$ (Fig. 3a). Except for MX and $\mathrm{LH}$ of $10-20 \mathrm{~cm}$ layer,
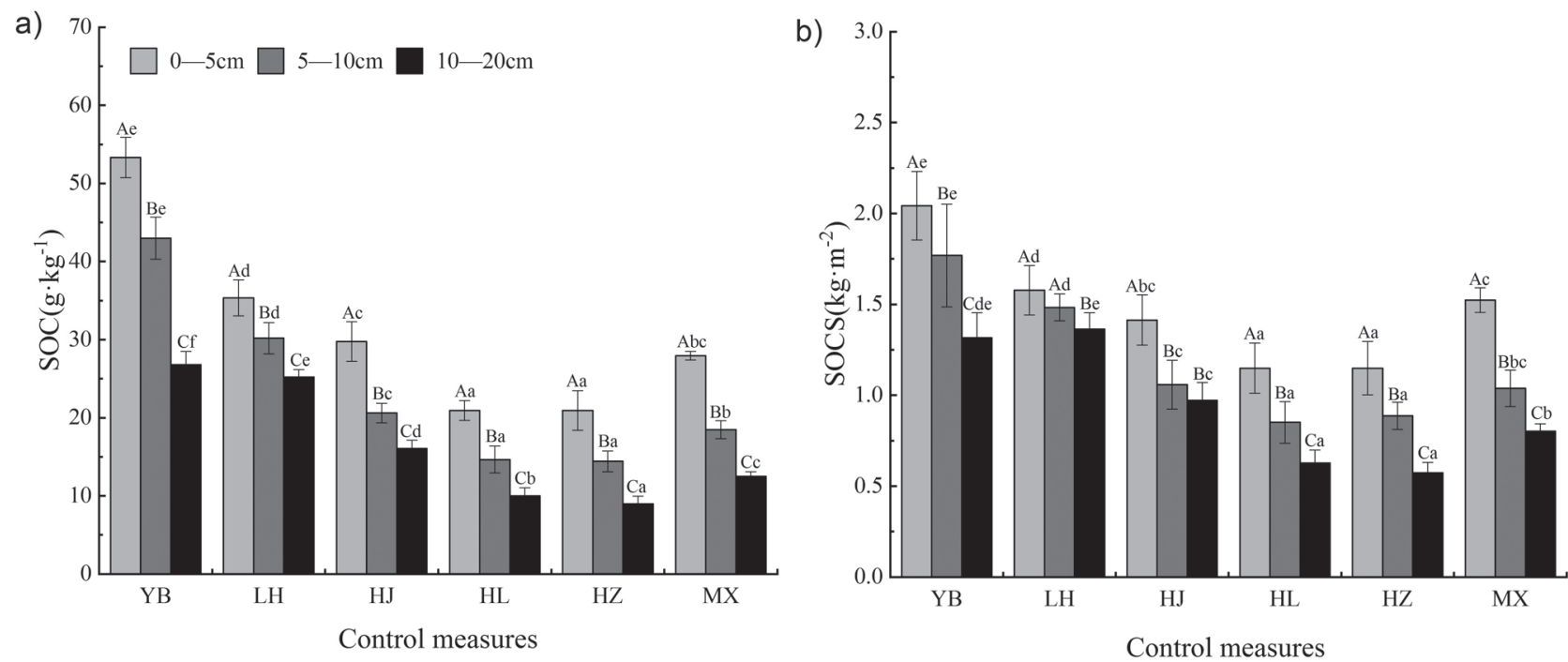

Fig. 2. Differences in a) soil organic carbon (SOC) content, b) soil organic carbon stocks at three soil depths of study measures: restoration with Sabina chinensis(YB); Abandoned and natural recovery (LH); restoration with Zanthoxylum bungeanum (HJ); restoration with Hylocereus undulates (HL); restoration with Pennisetum sinese (HZ); restoration with Medicago sativa (MX). Bars indicated \pm SD. Different lower case letters indicated a significant difference among different soil layers in the same forest type at 0.05 level, and different capital letters indicated a significant difference among different forest types in the same soil layer at 0.05 level. The same below. 
a)

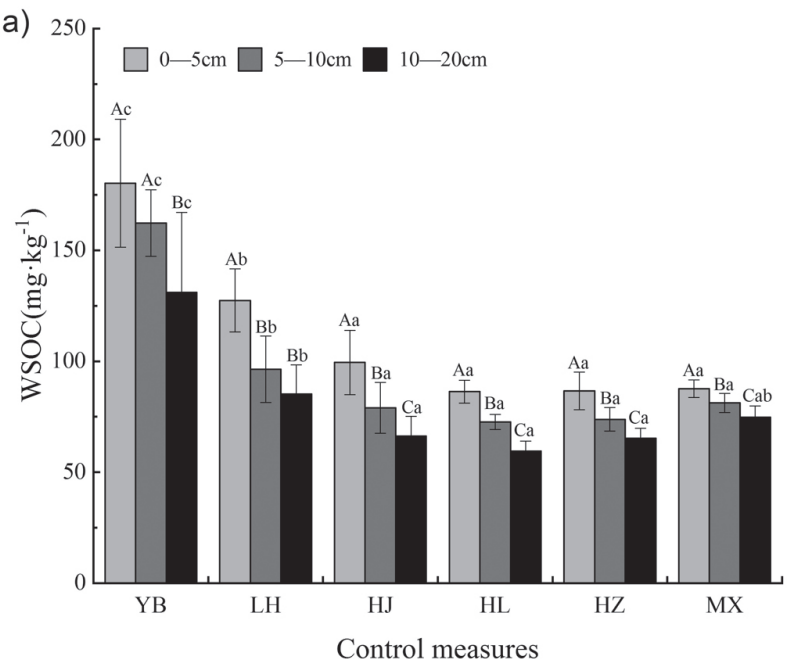

c)

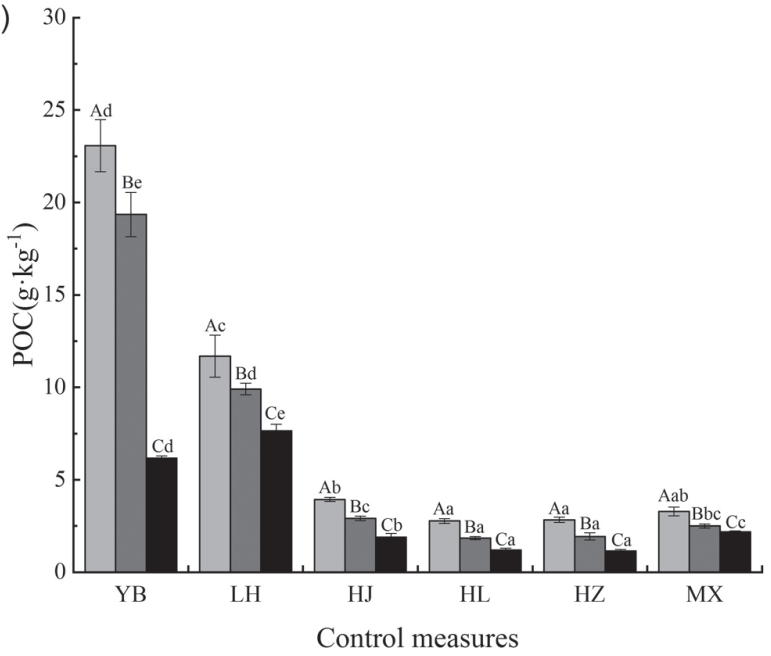

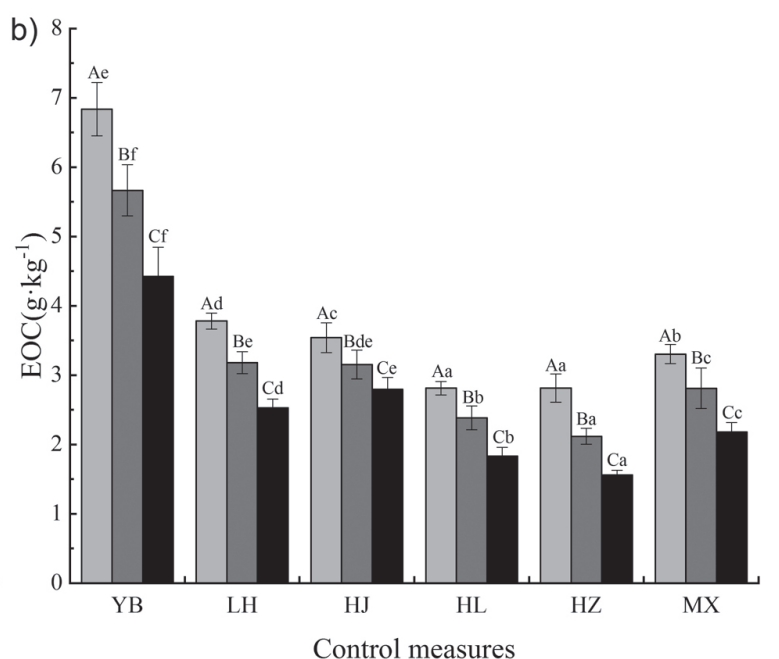

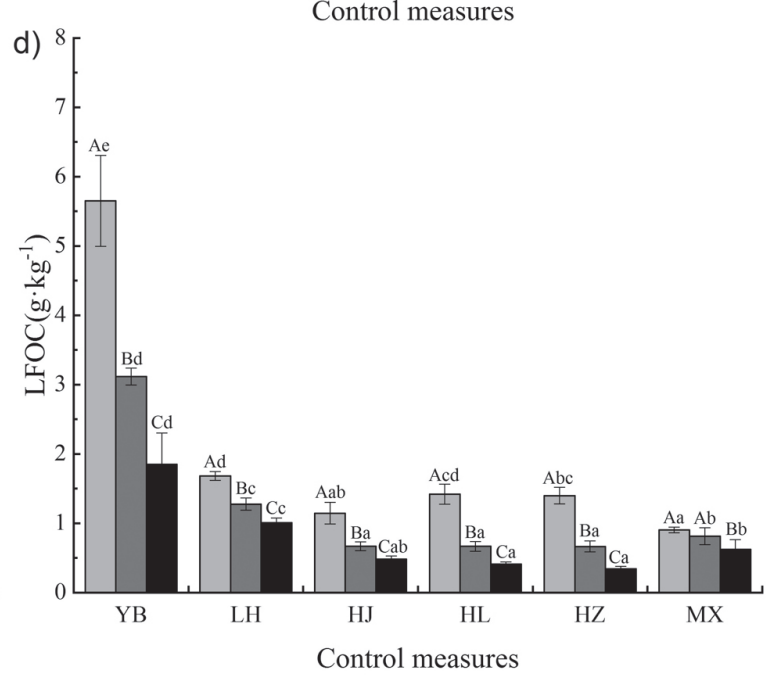

Fig. 3. Differences in LOC at three soil depths of study measures. a) water-soluble organic carbon (WSOC); b) easily oxidizable organic carbon (EOC); c) particulate organic carbon (POC); d) and light fraction organic carbon (LFOC). The same below.

the soil WSOC contents in the same soil layer of each measure were significantly higher than the other four measures, and there was no significant difference between the four measures. On the whole soil profile, the WSOC contents of each restoration measures decreased with the increase of soil depths, which was consistent with the change rule of SOC. The soil WSOC/SOC of all vegetation restoration measures ranged from $0.31 \%$ to $0.74 \%$, the maximum value occurring in $10-20 \mathrm{~cm}$ depth of HZ which was $0.74 \%$, and the minimum value occurring in $0-5 \mathrm{~cm}$ depth of MX which was $0.31 \%$ (Fig. 4a). On the soil profile, except for LH, the soil WSOC/SOC of each restoration measures showed an increase with the increase of the soil layer, which was opposite to the trend of soil WSOC content. The WSOC/SOC of LH soil showed a trend of falling first and then rising.

\section{Easily Oxidizable Organic Carbon}

The soil EOC contents of each vegetation restoration measures were 1.80 6.83 g/kg (Fig. 3b). Different restoration measures and soil layers have significant effects on soil EOC contents. There were significant differences in soil EOC contents of different restoration measures in the same soil layer. Among $0-5 \mathrm{~cm}$ soil layers, YB is the highest, followed by $\mathrm{LH}, \mathrm{HJ}$, and $\mathrm{MX}$, which were significantly higher than $\mathrm{HZ}$ and $\mathrm{HL}$, and there was no significant difference between HZ and HL. In the $5-10 \mathrm{~cm}$ depth, there were significant differences between the various measures except for $\mathrm{HJ}$ and $\mathrm{LH}$, and in the $10-20 \mathrm{~cm}$ depth, there were significant differences. The average value of the EOC contents of the $0-20 \mathrm{~cm}$ soil layer in each restoration measures was $\mathrm{YB}>\mathrm{LH}>\mathrm{HJ}>\mathrm{MX}>\mathrm{HL}>\mathrm{HL}$. In the vertical profile, the soil EOC contents of each restoration measures showed a tendency to decrease with the increase of soil layer depth, and each soil layer had significant differences. The soil WSOC/SOC of all vegetation restoration measures is between $0.31 \%$ and $0.74 \%$, with the maximum value occurring in $10-20 \mathrm{~cm}$ of $\mathrm{HZ}$ at $0.74 \%$, and the minimum value occurring in $0-5 \mathrm{~cm}$ of $\mathrm{MX}$ at $0.31 \%$ (Fig. $4 b$ ). In the soil profile, except for $\mathrm{LH}$, the soil EOC/SOC of each restoration measures increased 

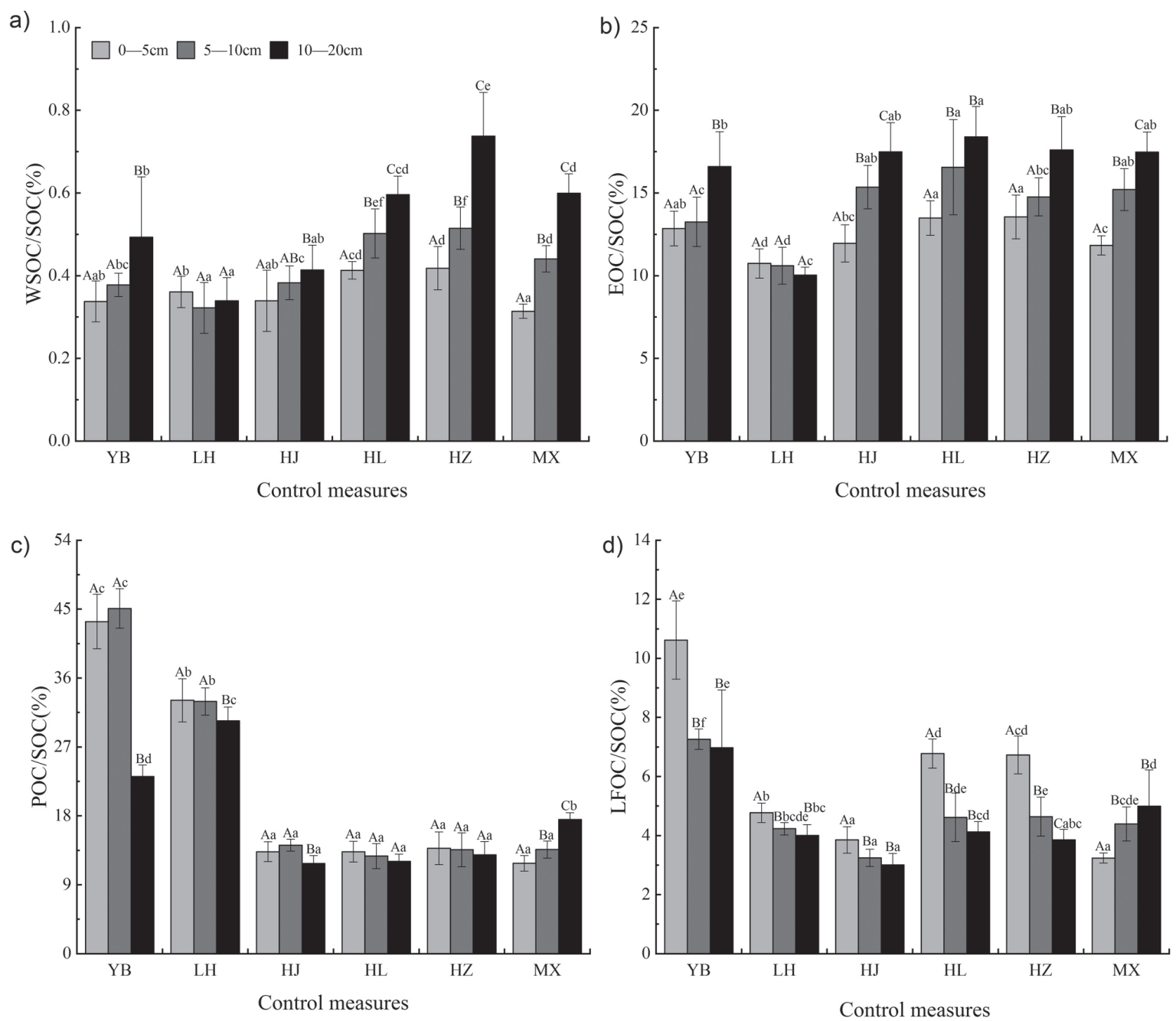

Fig. 4. Differences in LOC/SOC at three soil depths of study measures.

with the increase of depth, while LH decreased with the increase of soil layer.

\section{Particulate Organic Carbon}

It can be known from Fig. 3c) that the soil POC contents of each vegetation restoration measures were 1.14 to $23.07 \mathrm{~g} / \mathrm{kg}$. Different restoration measures and soil layers have significant effects on soil POC contents. The soil POC contents of each restoration measure showed the highest YB in any soil layer, followed by LH and the two were significantly higher than other measures. In the vertical profile, the variation of POC contents in each restoration measure was consistent with WSOC and EOC content, which decreased with the increase of soil layer, and there were significant differences among soil layers. In the $0-20 \mathrm{~cm}$ soil layer, the variation of soil $\mathrm{POC}$ contents in each restoration measure was $\mathrm{YB}>\mathrm{LH}>\mathrm{HJ}>\mathrm{MX}>\mathrm{HZ}>\mathrm{HL}$. The $\mathrm{POC} / \mathrm{SOC}$ range of each restoration measure was $11.79 \%$ to $45.08 \%$, in which $5-10 \mathrm{~cm}$ layer of YB is the largest at $45.08 \%$, and $10-20 \mathrm{~cm}$ layer of $\mathrm{HJ}$ is the smallest at $11.79 \%$ (Fig. 4c). In the vertical profile of soil, the regularity of soil POC/SOC changes was poor for each measure. As the soil layer increased, HL, $\mathrm{HZ}$, and $\mathrm{LH}$ decreased, HJ and YB increased first and then decreased, and MX increased with the soil layer increased. In the $0-20 \mathrm{~cm}$ layer, the soil POC contents under the different restoration measures decreased in the following order: $\mathrm{YB}>\mathrm{LH}>\mathrm{MX}>\mathrm{HZ}>\mathrm{HJ}>\mathrm{HL}$.

\section{Light Fraction Organic Carbon}

The soil LFOC contents of the six vegetation restoration measures were 0.45 to $5.65 \mathrm{~g} / \mathrm{kg}$ (Fig. 3d). Similar to the SOC, WSOC, EOC, and POC, the soil LFOC contents of each restoration measure in the same soil layer also showed that $\mathrm{YB}$ and $\mathrm{LH}$ were significantly higher than other restoration measures. In the $0-20 \mathrm{~cm}$ layer, the soil LFOC contents under the different restoration measures decreased in the following order: $\mathrm{YB}>\mathrm{LH}>\mathrm{HL}>\mathrm{HZ}>\mathrm{HJ}>\mathrm{MX}$. In the vertical profile of soil, the soil LFOC contents of the six restoration measures showed a trend of decreasing with the increase of soil depths, and all showed significant differences except for $0-5$ and 5-10 cm layer of MX. 
The LFOC/SOC range of each restoration measure was $3.01 \%$ to $10.62 \%$, in which $0-5 \mathrm{~cm}$ layer of $\mathrm{YB}$ was the largest at $10.62 \%$, and $10-20 \mathrm{~cm}$ layer of $\mathrm{HJ}$ was the smallest at $3.01 \%$ (Fig. 4d). In the soil profile, except MX increased with the increase of the soil layer, all the restoration measures showed a decrease with the increase of the soil layer.

\section{Changes in Soil Carbon Pool Management Index under Different Restoration Measures}

Soil carbon pool management index (CPMI) was calculated with the reference of LH (Table 1). The soil Non-labile organic carbon (NLC) contents of each restoration measures decreased with the increase of soil layer depths, and there were significant differences in each soil layers. The variation of soil NLC showed YB and LH were significantly higher than the other four measures, which was consistent with the soil SOC. In the $0-20 \mathrm{~cm}$ layer, the soil NLC contents under the different restoration measures decreased in the following order: $\mathrm{YB}>\mathrm{LH}>\mathrm{HJ}>\mathrm{MX}>\mathrm{HL}>\mathrm{HZ}$. Except for LH, the soil Lability of C (L) of each measure increased with the increase of soil depth, and LH decreased with the increase of soil depth. The soil L was higher than LH under different restoration measures in different soil layers. In the vertical profile of soil, the soil Lability index (LI) of YB, HJ, HL, $\mathrm{HZ}$, and MX increased with the increase of soil layer, and LH decreased first and then increased with the increase of soil layer depth. Soil LI was higher than $\mathrm{LH}$ in any layer of restoration measures. The soil carbon pool index (CPI) of each restoration measures decreased with the depth of the soil layer. The soil CPI of the other four restoration measures was less than LH except for YB. The soil CPMI of different restoration measures showed different trends in the vertical profile. Among them, HJ and MX showed an increase with the increase of soil depth, while HL increased first and then decreased, YB decreased first and then increased, and $\mathrm{HZ}$ decreased with the increase of soil layers. Except for the soil CPMI of YB and HJ under 5-10 and 10-20 cm soil layers, which were higher than $\mathrm{LH}$, the other measures were less than LH. In the 0-20 cm layer, the soil CPMI contents under the different restoration measures decreased in the following order: YB $\begin{array}{lll}(186.25)>\mathrm{HJ} \quad(107.16)>\mathrm{MX} \quad(92.28)>\mathrm{HL} \quad(79.36)>\mathrm{HZ} & \end{array}$ (71.58).

Table 1. Non-labile C (NLC), Lability of C (L), Lability index (LI), Carbon pool index (CPI), Carbon pool management index (CPMI) of different vegetation restoration measures.

\begin{tabular}{|c|c|c|c|c|c|c|}
\hline $\begin{array}{c}\text { Soil layer } \\
(\mathrm{cm})\end{array}$ & $\begin{array}{c}\text { Restoration } \\
\text { measures }\end{array}$ & NLC & $\mathrm{L}$ & LI & CPI & CPMI \\
\hline \multirow{6}{*}{$0-5$} & LH & $31.57 \pm 2.37 \mathrm{Ad}^{\mathrm{I}}$ & $0.12 \pm 0.01 \mathrm{Ad}$ & $1.00 \pm 0.00 \mathrm{Ad}$ & $1.00 \pm 0.00 \mathrm{Ab}$ & $100.00 \pm 0.00 \mathrm{Abc}$ \\
\hline & YB & $46.48 \pm 2.64 \mathrm{Ae}$ & $0.15 \pm 0.01 \mathrm{Aab}$ & $1.23 \pm 0.09 \mathrm{Aabc}$ & $1.51 \pm 0.10 \mathrm{Aa}$ & $185.15 \pm 6.72 \mathrm{Aa}$ \\
\hline & $\mathrm{HJ}$ & $26.23 \pm 2.50 \mathrm{Ac}$ & $0.14 \pm 0.01 \mathrm{Abc}$ & $1.13 \pm 0.12 \mathrm{Abc}$ & $0.84 \pm 0.08 \mathrm{Acd}$ & $95.01 \pm 6.13 \mathrm{Ac}$ \\
\hline & HL & $18.12 \pm 1.29 \mathrm{Aa}$ & $0.16 \pm 0.01 \mathrm{Aa}$ & $1.31 \pm 0.20 \mathrm{Aa}$ & $0.59 \pm 0.05 \mathrm{Aef}$ & $76.96 \pm 5.67 \mathrm{Af}$ \\
\hline & $\mathrm{HZ}$ & $18.12 \pm 2.40 \mathrm{Aa}$ & $0.16 \pm 0.02 \mathrm{Aa}$ & $1.31 \pm 0.13 \mathrm{Aa}$ & $0.59 \pm 0.06 \mathrm{Af}$ & $77.04 \pm 7.62 \mathrm{Aef}$ \\
\hline & MX & $24.62 \pm 0.59 \mathrm{Abc}$ & $0.13 \pm 0.01 \mathrm{Ac}$ & $1.13 \pm 0.15 \mathrm{Ac}$ & $0.79 \pm 0.05 \mathrm{Ad}$ & $88.7 \pm 6.82 \mathrm{Ad}$ \\
\hline \multirow{6}{*}{$5-10$} & LH & $27.01 \pm 2.12 \mathrm{Bd}$ & $0.12 \pm 0.01 \mathrm{Ad}$ & $1.00 \pm 0.00 \mathrm{Ac}$ & $1.00 \pm 0.00 \mathrm{Ab}$ & $100.00 \pm 0.00 \mathrm{Acd}$ \\
\hline & YB & $37.33 \pm 2.94 \mathrm{Be}$ & $0.15 \pm 0.02 \mathrm{Ac}$ & $1.30 \pm 0.20 \mathrm{Ab}$ & $1.43 \pm 0.12 \mathrm{Aa}$ & $183.99 \pm 15.75 \mathrm{Aa}$ \\
\hline & $\mathrm{HJ}$ & $17.45 \pm 1.25 \mathrm{Bc}$ & $0.18 \pm 0.02 \mathrm{Bab}$ & $1.56 \pm 0.33 \mathrm{Bab}$ & $0.69 \pm 0.09 \mathrm{Bc}$ & $105.21 \pm 12.05 \mathrm{Abc}$ \\
\hline & HL & $12.27 \pm 1.84 \mathrm{Ba}$ & $0.20 \pm 0.04 \mathrm{Ba}$ & $1.71 \pm 0.43 \mathrm{Ba}$ & $0.49 \pm 0.08 \mathrm{Bef}$ & $80.93 \pm 11.04 \mathrm{Aef}$ \\
\hline & $\mathrm{HZ}$ & $12.30 \pm 1.29 \mathrm{Ba}$ & $0.17 \pm 0.02 \mathrm{Abc}$ & $1.48 \pm 0.24 \mathrm{Aab}$ & $0.48 \pm 0.05 \mathrm{Bf}$ & $70.10 \pm 6.83 \mathrm{Bf}$ \\
\hline & MX & $15.67 \pm 0.98 \mathrm{Bb}$ & $0.18 \pm 0.02 \mathrm{Bab}$ & $1.54 \pm 0.31 \mathrm{Bab}$ & $0.61 \pm 0.06 \mathrm{Bd}$ & $93.88 \pm 15.23 \mathrm{Ad}$ \\
\hline \multirow{6}{*}{$10-20$} & LH & $22.67 \pm 0.91 \mathrm{Ce}$ & $0.11 \pm 0.01 \mathrm{Ac}$ & $1.00 \pm 0.00 \mathrm{Ac}$ & $1.00 \pm 0.00 \mathrm{Ab}$ & $100.00 \pm 0.00 \mathrm{Acd}$ \\
\hline & YB & $22.36 \pm 1.86 \mathrm{Cde}$ & $0.20 \pm 0.03 \mathrm{Bb}$ & $1.80 \pm 0.32 \mathrm{Bb}$ & $1.07 \pm 0.09 \mathrm{Ba}$ & $189.6 \pm 23.10 \mathrm{Aa}$ \\
\hline & $\mathrm{HJ}$ & $13.28 \pm 1.12 \mathrm{Cc}$ & $0.21 \pm 0.03 \mathrm{Cab}$ & $1.91 \pm 0.29 \mathrm{Cab}$ & $0.64 \pm 0.05 \mathrm{Bc}$ & $121.27 \pm 12.88 \mathrm{Bb}$ \\
\hline & HL & $8.19 \pm 0.96 \mathrm{Ca}$ & $0.23 \pm 0.03 \mathrm{Ba}$ & $2.03 \pm 0.28 \mathrm{Ca}$ & $0.40 \pm 0.03 \mathrm{Cef}$ & $80.20 \pm 8.87 \mathrm{Ae}$ \\
\hline & $\mathrm{HZ}$ & $7.40 \pm 1.01 \mathrm{Ca}$ & $0.21 \pm 0.03 \mathrm{Bab}$ & $1.92 \pm 0.25 \mathrm{Bab}$ & $0.36 \pm 0.05 \mathrm{Cf}$ & $67.59 \pm 4.01 \mathrm{Bf}$ \\
\hline & MX & $10.32 \pm 0.60 \mathrm{Cb}$ & $0.21 \pm 0.02 \mathrm{Cab}$ & $1.91 \pm 0.19 \mathrm{Cab}$ & $0.50 \pm 0.04 \mathrm{Cd}$ & $94.26 \pm 7.20 \mathrm{Ad}$ \\
\hline
\end{tabular}

${ }^{\mathrm{I}}$ Different lower case letters indicated the significant difference between different soil layers of the same vegetation restoration measure at $\alpha=0.05$, and different capital letters indicated the significant difference between different soil layers of the same vegetation restoration measure at $\alpha=0.05$. 
Relationship between SOC, LOC, and Soil Phy-Chemical Properties

The results of the correlation between SOC and LOC were shown in Fig. 5. The soil SOC was significantly positive correlated with WSOC, EOC, POC, and LFOC $(P<0.01)$, indicating that the soil LOC was mostly dependent on the SOC contents. Besides, the soil LOC also showed significant positive correlations with each other $(P<0.01)$, indicating that the labile fractions were closely related. Although their measurement methods and expressions were different, the results can reflect the changes in SOC.

The results of the correlation between SOC, LOC, CPMI, and other soil Phy-chemical properties were shown in Table 2. Soil SOC was positively correlated with soil $\mathrm{TN}, \mathrm{C} / \mathrm{N}, \mathrm{CPMI}$, and $\mathrm{G}(P<0.01)$, and negatively correlated with soil $\mathrm{BD}(P<0.01)$, but no correlation with $\mathrm{pH}$. Except for the soil EOC and $\mathrm{pH}$ were extremely significantly correlated $(P<0.01)$, there was no significant correlation between the LOC (WSOC, POC, LFOC) and pH. Each LOC had a significant positive correlation with soil $\mathrm{TN}, \mathrm{C} / \mathrm{N}$, CPMI, and $\mathrm{G}(P<0.01)$, had a extremely significant negative correlation with soil $\mathrm{BD}(P<0.01)$. Soil CPMI was positively correlated with soil $\mathrm{pH}, \mathrm{TN}, \mathrm{C} / \mathrm{N}$, and
$\mathrm{G}(P<0.01)$, and negatively correlated with soil $\mathrm{BD}$ $(P<0.01)$.

\section{Discussion}

\section{Impact of Different Vegetation Restoration Measures on SOC and SOCS}

Soil organic carbon (SOC) is a crucial indicator of soil quality evaluation in the process of vegetation restoration and reconstruction in karst ecosystems [16, 40]. Under natural conditions, the type of vegetation in a particular climatic area determines the quantity and quality of litter and root exudates returned to the soil. Differences in vegetation types will lead to differences in SOC and SOCS $[5,22,34]$. In this study, we found that there were significant differences in SOC contents and SOCS under different vegetation restoration measures for rocky desertification, among which YB was the highest, and LH was the second, both of which were significantly higher than the other four measures. These differences could be rationally attributed to the fact that these measures have less human disturbance and more litter on the surface. This is consistent with the results of $\mathrm{Lu}$ [47], who believe that in karst areas,

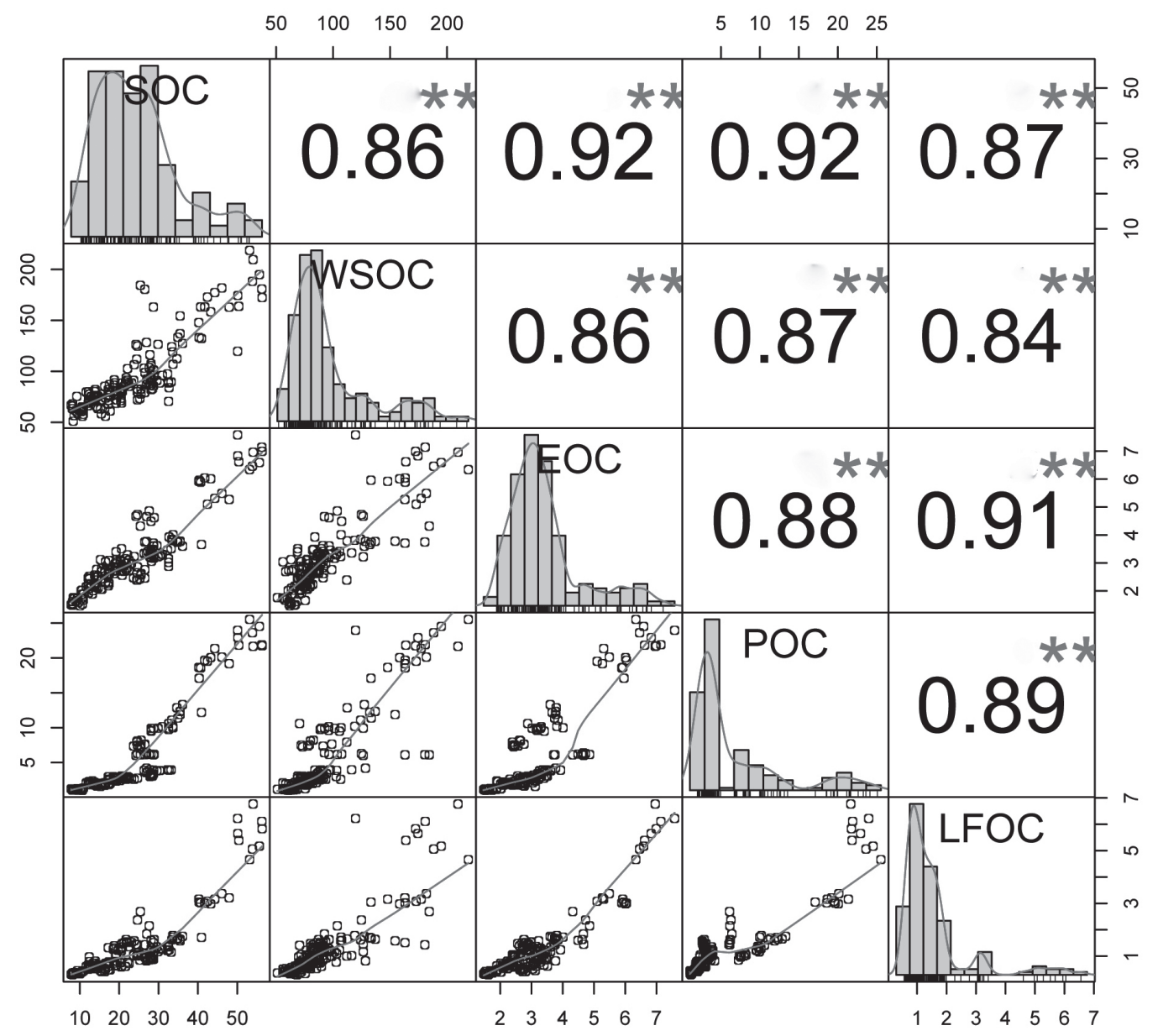

Fig. 5. Relationships between SOC and LOC (WSOC, EOC, POC, LFOC). ${ }^{* *}$ Correlation is significant at the 0.01 level. 
Table 2 Correlation analysis between soil SOC, LOC, CPMI, and soil phy-chemical properties.

\begin{tabular}{|c|c|c|c|c|c|c|}
\hline Items & BD & PH & TN & C/N & CPMI & G \\
\hline SOC & $-0.688^{* *+}$ & 0.108 & $0.956^{* *}$ & $0.803^{* *}$ & $0.685^{* *}$ & $0.813^{* *}$ \\
\hline WSOC & $-0.532^{* *}$ & 0.140 & $0.854^{* *}$ & $0.600^{* *}$ & $0.731^{* *}$ & $0.785^{* *}$ \\
\hline EOC & $-0.642^{* *}$ & $0.206^{* *}$ & $0.871^{* *}$ & $0.722^{* *}$ & $0.864^{* *}$ & $0.803^{* *}$ \\
\hline POC & $-0.515^{* *}$ & 0.102 & $0.907^{* *}$ & $0.610^{* *}$ & $0.725^{* *}$ & $0.883^{* *}$ \\
\hline LFOC & $-0.516^{* *}$ & 0.105 & $0.832^{* *}$ & $0.596^{* *}$ & $0.730^{* *}$ & $0.753^{* *}$ \\
\hline CPMI & $-0.399^{* *}$ & $0.259^{* *}$ & $0.639^{* *}$ & $0.551^{* *}$ & - & $0.753^{* *}$ \\
\hline
\end{tabular}

$I * *$ indicate the significant difference at $\alpha=0.01$.

reducing human disturbance and natural restoration were effective ways to improve soil quality. The SOC and SOCS decreased with soil depth in the soil profile, and the reduction range was different due to different types of vegetation. The proportion of SOC and SOCS in $0-5 \mathrm{~cm}$ soil under different restoration measures was $38.96 \% \sim 47.23 \%$ and $35.67 \% \sim 45.28 \%$ respectively, which were consistent with previous research results and showed visible surface aggregation [32-33, 48]. The main reason was that plant litter and roots were mostly distributed in the surface soil, and humus formed after decomposition was accumulated in the surface soil. On the other hand, this also shows that the stability of SOC in karst areas is reduced. Excessive human interference and unreasonable human activities are likely to cause soil erosion and rocky desertification. Therefore, it is vital to optimize the allocation and protection of forest and grass vegetation in karst areas and reduce unreasonable human activities for carbon management of rocky desertification soil.

\section{Impact of Different Vegetation Restoration Measures on LOC}

Soil LOC mainly comes from humic organic matter, plant litter, root exudates, and microbiome exudates. Compared with SOC, it has a faster turnover rate in soil and stronger sensitivity to the outside world, and it is more susceptible to the impact of vegetation types [30-31]. This study shows that the changes of soil LOC (WSOC, EOC, POC, and LFOC) and SOC under different restoration measures were consistent, and YB was the highest, followed by LH, both of which were significantly higher than the other four measures. This rule is mainly because SOC is the main factor affecting soil LOC, and the contents of soil LOC largely depends on the contents of SOC, When SOC is high, its labile carbon fractions are often high $[18,41]$. In the soil profile, the changing trend of LOC in each soil is consistent with SOC, which decreased with the deepening of soil depths, mainly due to the concentration of litter in the surface soil, the distribution of plant roots, and the more sufficient light, which were conducive to the growth and reproduction of microorganisms. With the deepening of soil layers, the increase of soil bulk density leads to the worse ventilation condition, the decrease of soil organic matter contents, and the decrease of underground biomass, resulting in a significant reduction of the labile organic carbon fractions in the subsoil $[19,30,38]$. Correlation analysis also showed that $\mathrm{SOC}$ and its labile fractions (WSOC, EOC, POC, LFOC) were significantly positive correlated $(P<0.01)$, which was consistent with previous research results $[12,18,30]$. The results show that WSOC, EOC, POC, and LFOC can be used as effective indicators to characterize soil organic carbon pool in the karst area [30, 49]. However, since soil LOC is extremely sensitive to environmental changes, it is difficult to keep the changes of each fraction utterly consistent with the SOC. For example, the degree of vertical decline of the LOC in the soil profile was different, among which the EOC of each restoration measures shows a significant difference in different soil layers, while the soil WSOC shows no significant difference in the $0-5$ and $5-10 \mathrm{~cm}$ soil layers of YB. All of these indicate that the change of soil LOC is affected by a variety of factors. Therefore, research on soil LOC should fully consider the complexity and diversity of its influencing factors [38].

The LOC/SOC is more reflective of the effect of vegetation on soil behavior than LOC $[11,50]$. This study showed that the soil WSOC/SOC of the six control measures ranged from $0.31 \%$ to $0.74 \%$. In the vertical profile of soil, the soil WSOC/SOC showed a characteristic of increasing with the increase of soil depths, which is opposite to the trend of soil WSOC contents. The reason is that soil WSOC activity is high, has certain mobility and solubility, and is prone to dissolution and migration $[13,18]$, which also indicate that deep soil SOC is better protected and more stable than surface soil [38]. Soil EOC/SOC is an indicator of soil carbon stability. When it is higher, which means that the soil carbon activity is greater and the stability is worse [22]. In this study, the soil EOC/SOC of various restoration measures ranged from $10.03 \%$ to $18.39 \%$. Among them, HL and HZ accounted for a large proportion, and LH was the smallest, indicating that the activity of SOC in LH is low, which is beneficial to the 
accumulation of SOC. Previous studies have pointed out that soil POC and LFOC represent unprotected fractions of SOC, and their ratios (POC/SOC, LFOC/SOC) reflect the relative soil amount of nonprotective or unstable SOC in China [21]. This study showed that the change trend of soil POC/SOC and LFOC/SOC is consistent with the change trend of soil POC and LFOC contents, both of which are higher under $\mathrm{YB}$ and $\mathrm{LH}$ management measures. The reason may be that YB and LH have less human disturbance, and there are more animal and plant residues on the surface. However, other management measures have less surface litter due to more human disturbance, especially $\mathrm{HJ}$ and $\mathrm{HZ}$, thus soil $\mathrm{POC} / \mathrm{SOC}$ and LFOC/ SOC are low.

\section{Responses of Soil CPMI to Different Restoration Measures and Their Implications for Rocky Desertification Vegetation Restoration Practices}

The soil CPMI can comprehensively and dynamically reflect the impact of different vegetation types and management measures on SOC pools from the quantity and quality of soil LOC. It is often used as an indicator of the change and renewal degree of SOC pools. When the value of CMPI is higher, it indicates that the soil management and management is more reasonable, and the soil quality develops to benign. On the contrary, it indicates that soil management is unreasonable, and the soil quality develops to malignant [13, 22]. This study shows that the soil CPMI of each measure in the $0-20 \mathrm{~cm}$ layer is YB (186.25)>HJ (107.16)>LH (100.00) $>$ MX (92.28) $>$ HL (79.36) $>$ HZ (71.58). Among them, the soil CPMI of each soil layer YB is greater than $\mathrm{LH}$, indicating that $\mathrm{YB}$ is an effective carbon sequestration measure of karst rocky desertification control, which is beneficial to the karst ecological environmental management and protection in Southwest China. The soil CPMI of HJ $0-5 \mathrm{~cm}$ is less than LH, which may be caused by more human interference. After the harvest of Zanthoxylum bungeanums, local farmers chose to remove all its litter, such as branches and leaves, resulting in less litter on the soil surface and lower soil nutrients. The soil CPMI of HJ 5-10 and $10-20 \mathrm{~cm}$ layer is higher than $\mathrm{LH}$, indicating that HJ has a positive effect on the accumulation of SOC in deep soil, which is consistent with the results of Liao [16]. Soil CPMI of $0-20 \mathrm{~cm}$ layer HJ is larger than that of $\mathrm{LH}$, and the economic benefit of $\mathrm{HJ}$ is higher than other measures. In Guanling region of Guizhou, a unique "Zanthoxylum bungeanums model" has been formed. Therefore, this article believes that Zanthoxylum bungeanums can be used as a priority economic species for the ecological restoration of karst rocky desertification and the development of mountain agriculture in Southwest China. The soil
CPMI of HL, HZ, and MX are low than that of LH, indicating that the ecological effects of the three restoration measures are worse than that of natural recovery. Also, the change rule of soil CPMI of various control measures is more consistent with SOC, and the correlation analysis also shows that there is significantly correlations between soil CPMI and various soil indicators $(P<0.01)$, which indicates that soil CPMI can be used as a sensitive indicator of soil management in karst areas.

\section{Conclusions}

(1) The SOC contents, SOCS, and soil LOC (WSOC, EOC, POC, LFOC) contents of different vegetation restoration measures for karst rocky desertification control were the highest in restoration with Sabina chinensis, followed by the natural recovery of abandoned land, which was significantly higher than the other four measures. From the vertical distribution of soil profile, the contents of each indexes decreased with the increase of soil depth.

(2) Taking the abandoned and natural recovery as a reference, in the $0-20 \mathrm{~cm}$ layer, the soil carbon pool management index under the different restoration measures decreased in the following order: restoration with Sabina chinensis>restoration with Zanthoxylum bungeanums $>$ restoration with Medicago sativas $>$ restoration with Hylocereus undulates $>$ restoration with Pennisetum sineses.

(3) Returning cultivated land to forests (Sabina chinensis) and abandonment of natural recovery are more conducive to karst ecological environment management and protection. Zanthoxylum bungeanums can be used as a priority economic species for karst rocky desertification and mountain agricultural development in Southwestern China.

(4) Soil WSOC, EOC, POC, and LFOC can be used as effective indicators to reflect SOC pools, and soil CPMI can also be used as a sensitive indicator to reflect soil management.

\section{Acknowledgements}

This work was supported by grants from the China National Natural Science Foundation (No. 31660136), the Key Project of Guizhou Science and Technology Fund (No. Qiankehe Jichu [2016]1414), the Support Plan for Science and Technology Top-notch Talents of Guizhou Higher Education Institutions (No. Qianjiaohe KY zi [2016]064), and the Support Plan for Excellent Young Science and Technology talents of Guizhou Province (No. Qiankehe Pingtai Rencai [2017]5638). 


\section{Conflict of Interest}

The authors declare no conflict of interest.

\section{References}

1. CAI Y.L. Preliminary research on ecological reconstruction in karst mountain poverty areas of southwest China. Adv. Earth Sci. 11 (6), 602, 1996.

2. BATJES N.H. Total carbon and nitrogen in the soils of the world. Eur. J. Soil Sci. 47, 151, 1996.

3. LAL R. Soil carbon sequestration impacts on global climate change and food security. Science 304 (5677), $1623,2004$.

4. SHANG Z.H., CAO J.J., GUO R.Y., LONG R.J. Effects of cultivation and abandonment on soil carbon content of subalpine meadows, northwest China. J. Soil Sediment. 12, 826, 2012.

5. HU P.L., LIU S.J., YE Y.Y., ZHANG W., WANG K.L., SU Y.R. Effects of environmental factors on soil organic carbon under natural or managed vegetation restoration. Land Degrad. Dev. 29, 387, 2018.

6. SONG B., NIU S.L., LI L.H., ZHANG L.X., YU G.R. Soil carbon fractions in grasslands respond differently to various levels of nitrogen enrichments. Plant Soil. 384, 401, 2014.

7. YANG H., ZHOU L., HUANG L.Y., CAO J.H., GROVES C. A comparative study of soil carbon transfer between forest soils in subtropical karst and clasolite areas and the karst carbon sink effect in Guilin, Guangxi, China. Environ. Earth Sci. 74, 921, 2015.

8. GUIDI C., MAGID J., RODEGHIERO M., GIANELLE D., VESTERDAL L. Effects of forest expansion on mountain grassland: changes within soil organic carbon fractions. Plant Soil. 385, 373, 2014

9. SOLLINS P., HOMANN P., CALDWELL, B.A. Stabilization and destabilization of soil organic matter: mechanisms and controls. Geoderma. 74, 65, 1996.

10. PAUL E.A., HARRIS D., COLLINS H.P., SCHULTHESS U., ROBERTSON G.P. Evolution of $\mathrm{CO}_{2}$ and soil carbon dynamics in biologically managed, row-crop agroecosystems. Appl. Soil Ecol. 11 (1), 53, 1999.

11. ZHANG Z.M., ZHOU Y.C., WANG S.J., HUANG X.F. Comparing estimation methods for soil organic carbon storage in small karst watersheds. Pol. J. Environ. Stud. 27 (4), 1879, 2018.

12. WANG X.L., XU J.Y., WU Z.S., SHEN Y.C., CAI, Y.J. Effect of annual prescribed burning of wetlands on soil organic carbon fractions: A 5-year study in Poyang, China. Eco. Eng. 138, 219, 2019.

13. BANGER K., TOOR G.S., BISWAS A., SIDHU S.S., SUDHIR K. Soil organic carbon fractions after 16-years of applications of fertilizers and organic manure in a Typic Rhodalfs in semi-arid tropics. Nutr. Cycl. Agroe. 86, 391, 2010.

14. LIU E.K., TECLEMARIAM S.G., YAN C.R., YU J.M., GU R.S., LIU S., HE W.Q., LIU Q. Long-term effects of no-tillage management practice on soil organic carbon and its fractions in the northern China. Geoderma. 213, 379, 2014.

15. LI L.Q., WANG D., LIU X.Y., ZHANG B., LIU Y.Z., XIE T., DU Y.X., PAN G.X. Soil organic carbon fractions and microbial community and functions under changes in vegetation: a case of vegetation succession in karst forest.
Environ. Earth Sci. 71, 3727, 2014.

16. LIAO H.K., LONG J., LI J. Soil organic carbon associated in size-fractions as affected by different land uses in karst region of Guizhou, Southwest China. Environ. Earth Sci. 74, 6877, 2016.

17. NIU X., GAO P., LI Y.X., LI X. Impact of different afforestation systems on soil organic carbon distribution characteristics of limestone mountains. Pol. J. Environ. Stud. 24 (6), 2543, 2015.

18. PANG D.B., CUI M., LIU Y.G., WANG G.Z., CAO J.H., WANG X.R., DAN X.Q., ZHOU Z.X. Responses of soil labile organic carbon fractions and stocks to different vegetation restoration strategies in degraded karst ecosystems of southwest China. Eco. Eng. 138, 391, 2019.

19. YANG X.Y., REN W.D., SUN B.H., ZHANG S.L. Effects of contrasting soil management regimes on total and labile soil organic carbon fractions in a loess soil in China. Geoderma. 177, 49, 2012.

20. YANG Y.S., GUO J.F., CHEN G.S., YIN Y.F., GAO R., LIN C.F. Effects of forest conversion on soil labile organic carbon fractions and aggregate stability in subtropical China. Plant Soil. 323, 153, 2009.

21. LI J., WEN Y.C., LI X.H., LI Y.T., YANG X.D., LIN Z.A., SONG Z.Z., COOPER J.M., ZHAO B.Q. Soil labile organic carbon fractions and soil organic carbon stocks as affected by long-term organic and mineral fertilization regimes in the North China Plain. Soil Till. Res. 175, 281, 2018.

22. LI Z.W., NIE X.D., CHEN X.L., LU Y.M., JIANG W.G., ZENG G.M. The effects of land use and landscape position on labile organic carbon and carbon management index in red soil hilly region, southern China. J. Mount. Sci. 12, 626, 2015.

23. YANG C.M., YANG L.Z., ZHU O.Y. Organic carbon and its fractions in paddy soil as affected by different nutrient and water regimes. Geoderma. 124, 133, 2005.

24. ZHANG L.H., XIE Z.H., ZHAO R.F., WANG Y.J. The impact of land use change on soil organic carbon and labile organic carbon stocks in the Longzhong region of Loess Plateau. J. Arid Land. 4 (3), 241, 2012.

25. QIU H.S., LIU J.Y., LI L., LIU K.P., HE X.Y., SU Y.R. Assessing nutrient elements as indicators for soil active organic carbon in topsoil of karst areas. Pol. J. Environ. Stud. 28 (3), 1325, 2019.

26. GARTEN C.T., JR POST.III.W.M., HANSON P.J., COOPER L.W. Forest soil carbon inventories and dynamics along an elevation gradient in the southern Appalachian mountains. Biogeochemistry. 45 (2), 115, 1999.

27. HUO L., PANG H.C., ZHAO Y.G., WANG J., LU C., LI Y.Y. Buried straw layer plus plastic mulching improves soil organic carbon fractions in an arid saline soil from Northwest China. Soil Till. Res. 165, 286, 2017.

28. BOLINDER M., ANGERS D., GREGORICH E., CARTER $\mathrm{M}$. The response of soil quality indicators to conservation management. Can. J. Soil Sci. 79, 37, 1999.

29. BLAIR G.J., LEFROY R.D.B., LISLE L. Soil carbon fractions based on their degree of oxidation and the development of a carbon management index for agricultural systems. Aust. J. Agr. Res. 46, 1459, 1995.

30. YANG X., WANG D., LAN Y., MENG J., JIANG L.L., SUN Q., CAO D.Y., SUN Y.Y., CHEN W.F. Labile organic carbon fractions and carbon pool management index in a 3-year field study with biochar amendment. J. Soil Sediment. 18, 1569, 2017.

31. JIANG Z.C., LIAN Y.Q., QIN X.Q. Rocky desertification in Southwest China: Impacts, causes, and restoration. 
Earth Sci. Rev. 132, 1, 2014.

32. SHENG M.Y., XIONG K.N., WANG L.J., LI X.N., LI R., TIAN X.J. Response of soil physical and chemical properties to Rocky desertification succession in South China Karst. Carbonate Evapo. 33 (19), 1, 2018.

33. ZHANG Z.M., ZHOU Y.C., WANG S.J., HUANG X.F. Soil organic carbon density spatial distribution and influencing factors in a karst mountainous basin. Pol. J. Environ. Stud. 26 (5), 2363, 2017.

34. CHEN H.S., ZHANG W., WANG K., HOU Y. Soil organic carbon and total nitrogen as affected by land use types in karst and non-karst areas of northwest Guangxi, China. J. Sci. Food Agr. 92, 1086, 2012.

35. ZHANG H., WU P.B., FAN M.M., ZHENG S.Y., WU J.T., YANG X.H., ZHANG M., YIN A.J., GAO C. Dynamics and driving factors of the organic carbon fractions in agricultural land reclaimed from coastal wetlands in eastern China. Ecol. Indic. 89, 639, 2018.

36. XU E.Q., ZHANG H.Q., LI M.X. Mining spatial information to investigate the evolution of karst rocky desertification and its human driving forces in Changshun, China. Sci. Total Environ. 458-460, 419, 2013.

37. LIU S.J., ZHANG W., WANG K.L., PAN F.J., YANG S., SHU S.Y. Factors controlling accumulation of soil organic carbon along vegetation succession in a typical karst region in Southwest China. Sci. Total Envir. 521-522, 52, 2015.

38. XIAO K.C., HE T.G., CHEN H., PENG W.X., SONG T.Q., WANG K.L., LI D.J. Impacts of vegetation restoration strategies on soil organic carbon and nitrogen dynamics in a karst area, southwest China. Eco. Eng. 101, 247, 2017.

39. ZHANG Y.H., XU X.L., LI Z.W., LIU M.X., XU C.H., ZHANG R.F., LUO W. Effects of vegetation restoration on soil quality in degraded karst landscapes of southwest China. Sci. Total environ. 650, 2657, 2019.

40. WANG L.J., WANG P., SHENG M.Y., TIAN J. Ecological stoichiometry and environmental influencing factors of soil nutrients in the karst rocky desertification ecosystem, southwest China. Glob. Ecol. Conserv. 16, 1, 2018.
41. WANG M.M., CHEN H.S., ZHANG W., WANG K.L. Soil nutrients and stoichiometric ratios as affected by land use and lithology at county scale in a karst area, southwest China. Sci. Total environ. 619-620, 1299, 2018.

42. CHEN H., LI D.J., MAO Q.G., XIAO K.C., WANG K.L. Resource limitation of soil microbes in karst ecosystems. Sci. Total Envir. 650, 241, 2019.

43. BAO S.D. Soil and agricultural chemistry analysis. Chinese Agricultural Press Beijing, 2008 [In Chinese].

44. JONES D.L., WILLETT V.B. Experimental evaluation of methods to quantify dissolved organic nitrogen (DON) and dissolved organic carbon (DOC) in soil. Soil Biol. Bioch. 38, 991, 2006.

45. CAMBERDELlA C.A., ELLIOTT E.T. Particulate soil organic matter across a grassland cultivate-on sequence. Soil Sci. Soc. Am. J. 56 (3), 777, 1992.

46. JANZEN H.H., CAMPBELL C.A., BRANDT S.A., LAFOND G.P., TOWNLEY-SMITH L. Light-fraction organic matter in soils from long-term crop rotations. Soil Sci. Soc. Am. J. 56, 1799, 1992.

47. LU X.Q., TODA H., DING F.J., FANG S.Z., YANG W.X., XU H.G. Effect of vegetation types on chemical and biological properties of soils of karst ecosystems. Eur. J. Soil Biol. 61, 49, 2014.

48. XIAO Y., HUANG Z.G., LU X.G. Changes of soil labile organic carbon fractions and their relation to soil microbial characteristics in four typical wetlands of Sanjiang Plain, Northeast China. Eco. Eng. 82, 381, 2015.

49. XU X.R., ZHANG W.J., XU M.G., LI S.Y., AN T.T., PEI J.B., XIAO J., XIE H.T., WANG J.K. Characteristics of differently stabilised soil organic carbon fractions in relation to long-term fertilisation in Brown Earth of Northeast China. Sci. Total environ. 572, 1101, 2016.

50. DANIEL P.B., JORGE A.F., CARLOS C.M. Identifying soil organic carbon fractions sensitive to agricultural management practices. Soil Till. Res. 139, 19, 2014. 


\section{Supplementary Material}

Table S1. Data of soil basic physical and chemical properties and soil carbon pool management index.

\begin{tabular}{|c|c|c|c|c|c|c|c|c|c|c|c|c|}
\hline $\begin{array}{c}\text { Serial } \\
\text { number }\end{array}$ & $\begin{array}{c}\text { Soil } \\
\text { layer }\end{array}$ & $\begin{array}{c}\text { No. of } \\
\text { sample plot }\end{array}$ & $\begin{array}{c}\mathrm{BD} \\
\left(\mathrm{g} / \mathrm{cm}^{3}\right)\end{array}$ & PH & $\begin{array}{c}\mathrm{TN} \\
(\mathrm{g} / \mathrm{kg})\end{array}$ & $\mathrm{C} / \mathrm{N}$ & $\begin{array}{c}G \\
(\%)\end{array}$ & NLC & $\mathrm{L}$ & LI & CPI & CPMI \\
\hline 1 & $0-5$ & I-1-1 & 0.92 & 7.16 & 2.23 & 13.60 & 0.02 & 27.07 & 0.12 & 1.23 & 0.74 & 90.87 \\
\hline 2 & & I-1-2 & 0.91 & 7.16 & 2.15 & 13.38 & 0.01 & 25.15 & 0.14 & 1.20 & 0.82 & 98.55 \\
\hline 3 & & I-1-3 & 0.90 & 7.12 & 2.28 & 12.97 & 0.01 & 25.96 & 0.14 & 1.26 & 0.82 & 102.91 \\
\hline 4 & & I-2-1 & 0.97 & 7.11 & 1.94 & 13.58 & 0.01 & 23.00 & 0.15 & 1.18 & 0.76 & 89.82 \\
\hline 5 & & I-2-2 & 0.96 & 7.06 & 2.02 & 13.77 & 0.02 & 24.46 & 0.14 & 1.07 & 0.83 & 88.93 \\
\hline 6 & & I-2-3 & 1.06 & 7.05 & 2.05 & 13.14 & 0.00 & 23.16 & 0.16 & 1.21 & 0.80 & 96.45 \\
\hline 7 & & I-3-1 & 0.99 & 7.16 & 2.16 & 15.37 & 0.02 & 29.68 & 0.12 & 0.91 & 0.99 & 90.18 \\
\hline 8 & & I-3-2 & 1.01 & 7.13 & 2.09 & 15.45 & 0.00 & 28.83 & 0.12 & 1.01 & 0.91 & 91.87 \\
\hline 9 & & I-3-3 & 0.92 & 7.09 & 2.17 & 15.05 & 0.00 & 28.74 & 0.14 & 1.15 & 0.92 & 105.49 \\
\hline 10 & $5-10$ & I-1-1 & 0.99 & 7.13 & 1.64 & 11.67 & 0.07 & 16.17 & 0.18 & 1.71 & 0.59 & 100.81 \\
\hline 11 & & I-1-2 & 1.03 & 7.17 & 1.66 & 11.66 & 0.05 & 16.32 & 0.19 & 1.82 & 0.59 & 108.34 \\
\hline 12 & & I-1-3 & 1.05 & 7.21 & 1.59 & 12.08 & 0.05 & 15.81 & 0.21 & 2.21 & 0.59 & 130.61 \\
\hline 13 & & I-2-1 & 1.15 & 7.10 & 1.48 & 15.21 & 0.06 & 19.41 & 0.16 & 1.25 & 0.80 & 100.27 \\
\hline 14 & & I-2-2 & 1.15 & 7.17 & 1.61 & 13.42 & 0.07 & 18.45 & 0.17 & 1.29 & 0.77 & 98.98 \\
\hline 15 & & I-2-3 & 1.2 & 7.11 & 1.46 & 15.15 & 0.03 & 18.83 & 0.17 & 1.27 & 0.79 & 99.56 \\
\hline 16 & & I-3-1 & 1.03 & 7.13 & 1.66 & 12.28 & 0.03 & 17.33 & 0.18 & 1.43 & 0.71 & 101.06 \\
\hline 17 & & I-3-2 & 1.01 & 7.12 & 1.58 & 12.99 & 0.00 & 17.65 & 0.16 & 1.36 & 0.66 & 90.04 \\
\hline 18 & & I-3-3 & 1 & 7.16 & 1.61 & 12.79 & 0.00 & 17.08 & 0.21 & 1.70 & 0.69 & 117.27 \\
\hline 19 & $10-20$ & I-1-1 & 1.15 & 7.18 & 1.30 & 10.98 & 0.00 & 11.51 & 0.24 & 2.35 & 0.54 & 126.74 \\
\hline 20 & & I-1-2 & 1.13 & 7.13 & 1.31 & 12.47 & 0.00 & 13.61 & 0.20 & 1.86 & 0.66 & 123.31 \\
\hline 21 & & I-1-3 & 1.2 & 7.10 & 1.29 & 11.82 & 0.00 & 12.13 & 0.26 & 2.30 & 0.60 & 137.57 \\
\hline 22 & & I-2-1 & 1.18 & 7.19 & 1.23 & 12.64 & 0.00 & 12.74 & 0.22 & 1.93 & 0.61 & 117.49 \\
\hline 23 & & I-2-2 & 1.21 & 7.05 & 1.25 & 13.84 & 0.00 & 14.67 & 0.18 & 1.48 & 0.70 & 104.42 \\
\hline 24 & & I-2-3 & 1.39 & 7.06 & 1.27 & 12.84 & 0.01 & 13.66 & 0.19 & 1.67 & 0.61 & 102.64 \\
\hline 25 & & I-3-1 & 1.16 & 7.11 & 1.33 & 11.61 & 0.00 & 12.75 & 0.21 & 1.81 & 0.65 & 118.12 \\
\hline 26 & & I $-3-2$ & 1.19 & 7.02 & 1.28 & 13.82 & 0.00 & 14.95 & 0.18 & 1.72 & 0.70 & 120.58 \\
\hline 27 & & I-3-3 & 1.28 & 7.08 & 1.36 & 12.15 & 0.01 & 13.48 & 0.23 & 2.08 & 0.68 & 140.53 \\
\hline 28 & $0-5$ & II-1-1 & 1.04 & 7.05 & 1.79 & 11.56 & 0.04 & 17.79 & 0.16 & 1.66 & 0.51 & 84.24 \\
\hline 29 & & II-1-2 & 1.08 & 7.04 & 1.75 & 12.59 & 0.03 & 19.20 & 0.15 & 1.23 & 0.63 & 77.52 \\
\hline 30 & & II-1-3 & 1.16 & 7.07 & 1.81 & 12.02 & 0.04 & 18.78 & 0.16 & 1.43 & 0.60 & 86.25 \\
\hline 31 & & II-2-1 & 1.17 & 7.01 & 1.77 & 12.00 & 0.04 & 18.54 & 0.15 & 1.19 & 0.61 & 72.69 \\
\hline 32 & & II-2-2 & 1.13 & 7.00 & 1.76 & 12.75 & 0.02 & 19.72 & 0.14 & 1.08 & 0.67 & 72.03 \\
\hline 33 & & II-2-3 & 1.26 & 6.93 & 1.72 & 12.65 & 0.01 & 18.99 & 0.15 & 1.08 & 0.65 & 69.46 \\
\hline 34 & & II-3-1 & 1.12 & 7.00 & 1.83 & 10.77 & 0.00 & 16.86 & 0.17 & 1.29 & 0.59 & 76.12 \\
\hline 35 & & II-3-2 & 1.16 & 7.02 & 1.80 & 11.27 & 0.00 & 17.57 & 0.15 & 1.30 & 0.57 & 74.15 \\
\hline 36 & & II-3-3 & 0.96 & 7.04 & 1.74 & 10.63 & 0.02 & 15.62 & 0.18 & 1.54 & 0.52 & 80.18 \\
\hline 37 & $5-10$ & II-1-1 & 1.17 & 7.10 & 1.35 & 11.44 & 0.04 & 13.01 & 0.19 & 1.74 & 0.47 & 82.69 \\
\hline 38 & & II-1-2 & 1.11 & 7.11 & 1.33 & 10.77 & 0.04 & 11.93 & 0.20 & 1.96 & 0.44 & 86.18 \\
\hline 39 & & II-1-3 & 1.2 & 7.09 & 1.29 & 11.37 & 0.03 & 12.13 & 0.21 & 2.15 & 0.45 & 96.96 \\
\hline
\end{tabular}


Table S1. Continued

\begin{tabular}{|c|c|c|c|c|c|c|c|c|c|c|c|c|}
\hline 40 & & II-2-1 & 1.13 & 7.14 & 1.35 & 12.76 & 0.02 & 15.05 & 0.14 & 1.14 & 0.61 & 69.61 \\
\hline 41 & & II-2-2 & 1.16 & 7.13 & 1.27 & 13.03 & 0.00 & 14.24 & 0.16 & 1.22 & 0.59 & 72.06 \\
\hline 42 & & II-2-3 & 1.34 & 7.15 & 1.25 & 12.31 & 0.00 & 13.33 & 0.15 & 1.12 & 0.55 & 61.31 \\
\hline 43 & & II-3-1 & 1.16 & 7.14 & 1.21 & 10.02 & 0.00 & 9.66 & 0.25 & 2.06 & 0.42 & 86.63 \\
\hline 44 & & II-3-2 & 1.15 & 7.10 & 1.37 & 9.04 & 0.00 & 9.87 & 0.26 & 2.13 & 0.40 & 85.36 \\
\hline 45 & & II-3-3 & 1.18 & 7.14 & 1.39 & 9.90 & 0.00 & 11.18 & 0.23 & 1.90 & 0.46 & 87.56 \\
\hline 46 & $10-20$ & II-1-1 & 1.19 & 7.10 & 1.09 & 9.72 & 0.02 & 8.71 & 0.22 & 2.11 & 0.40 & 84.30 \\
\hline 47 & & II-1-2 & 1.22 & 7.04 & 1.02 & 10.13 & 0.02 & 8.32 & 0.24 & 2.25 & 0.42 & 94.29 \\
\hline 48 & & II-1-3 & 1.21 & 7.08 & .99 & 10.66 & 0.00 & 8.52 & 0.24 & 2.14 & 0.41 & 88.39 \\
\hline 49 & & II-2-1 & 1.24 & 7.11 & .86 & 12.38 & 0.00 & 8.90 & 0.20 & 1.72 & 0.42 & 71.73 \\
\hline 50 & & II-2-2 & 1.28 & 7.14 & .92 & 11.87 & 0.01 & 9.03 & 0.21 & 1.73 & 0.44 & 76.95 \\
\hline 51 & & II-2-3 & 1.4 & 7.08 & .97 & 11.20 & 0.00 & 9.19 & 0.18 & 1.56 & 0.41 & 64.04 \\
\hline 52 & & II-3-1 & 1.25 & 7.11 & .95 & 8.76 & 0.00 & 6.56 & 0.27 & 2.30 & 0.35 & 80.94 \\
\hline 53 & & II-3-2 & 1.22 & 7.04 & 1.08 & 8.69 & 0.00 & 7.65 & 0.23 & 2.14 & 0.37 & 79.43 \\
\hline 54 & & II-3-3 & 1.32 & 7.06 & 1.03 & 8.31 & 0.00 & 6.83 & 0.25 & 2.34 & 0.35 & 81.73 \\
\hline 55 & $0-5$ & III-1-1 & 1.09 & 7.09 & 2.14 & 10.81 & 0.03 & 20.15 & 0.15 & 1.51 & 0.57 & 85.42 \\
\hline 56 & & III-1-2 & 1.06 & 6.95 & 2.11 & 11.69 & 0.02 & 21.80 & 0.13 & 1.09 & 0.71 & 77.24 \\
\hline 57 & & III-1-3 & 1.21 & 7.03 & 2.09 & 11.39 & 0.01 & 20.58 & 0.16 & 1.41 & 0.66 & 93.24 \\
\hline 58 & & III-2-1 & 1.12 & 6.99 & 1.99 & 9.42 & 0.03 & 16.13 & 0.16 & 1.32 & 0.54 & 71.57 \\
\hline 59 & & III-2-2 & 1.11 & 7.01 & 2.03 & 9.21 & 0.05 & 15.99 & 0.17 & 1.33 & 0.56 & 73.75 \\
\hline 60 & & III-2-3 & 1.14 & 7.02 & 2.01 & 8.57 & 0.00 & 14.44 & 0.19 & 1.43 & 0.51 & 73.05 \\
\hline 61 & & III-3-1 & 1.15 & 7.00 & 1.89 & 10.87 & 0.06 & 17.71 & 0.16 & 1.23 & 0.62 & 75.72 \\
\hline 62 & & III-3-2 & 1.14 & 7.01 & 1.91 & 10.90 & 0.02 & 18.08 & 0.15 & 1.27 & 0.59 & 74.49 \\
\hline 63 & & III-3-3 & 1.12 & 7.03 & 1.85 & 11.22 & 0.01 & 18.20 & 0.14 & 1.18 & 0.58 & 68.90 \\
\hline 64 & $5-10$ & III-1-1 & 1.20 & 7.12 & 1.53 & 11.40 & 0.02 & 15.18 & 0.15 & 1.39 & 0.54 & 74.45 \\
\hline 65 & & III-1-2 & 1.26 & 7.12 & 1.49 & 8.99 & 0.02 & 11.38 & 0.18 & 1.73 & 0.41 & 71.05 \\
\hline 66 & & III-1-3 & 1.21 & 7.15 & 1.55 & 8.98 & 0.00 & 11.69 & 0.19 & 1.96 & 0.43 & 83.84 \\
\hline 67 & & III-2-1 & 1.22 & 7.04 & 1.58 & 9.87 & 0.00 & 13.54 & 0.15 & 1.19 & 0.55 & 66.20 \\
\hline 68 & & III-2-2 & 1.22 & 7.11 & 1.56 & 8.81 & 0.00 & 11.58 & 0.19 & 1.41 & 0.49 & 69.16 \\
\hline 69 & & III-2-3 & 1.33 & 7.11 & 1.61 & 9.07 & 0.00 & 12.50 & 0.17 & 1.21 & 0.52 & 63.03 \\
\hline 70 & & III-3-1 & 1.25 & 7.03 & 1.74 & 7.87 & 0.00 & 11.49 & 0.19 & 1.55 & 0.48 & 73.96 \\
\hline 71 & & III-3-2 & 1.21 & 7.14 & 1.65 & 8.61 & 0.02 & 12.06 & 0.18 & 1.48 & 0.46 & 67.99 \\
\hline 72 & & III-3-3 & 1.27 & 7.06 & 1.63 & 8.10 & 0.01 & 11.31 & 0.17 & 1.38 & 0.44 & 61.21 \\
\hline 73 & $10-20$ & III-1-1 & 1.26 & 7.15 & 1.25 & 7.17 & 0.02 & 7.33 & 0.22 & 2.17 & 0.34 & 73.48 \\
\hline 74 & & III-1-2 & 1.28 & 7.13 & 1.26 & 7.66 & 0.00 & 8.06 & 0.20 & 1.84 & 0.39 & 71.93 \\
\hline 75 & & III-1-3 & 1.29 & 7.13 & 1.19 & 7.76 & 0.00 & 7.57 & 0.22 & 1.96 & 0.36 & 70.77 \\
\hline 76 & & III-2-1 & 1.28 & 7.03 & 1.24 & 6.28 & 0.00 & 6.28 & 0.24 & 2.11 & 0.30 & 64.16 \\
\hline 77 & & III-2-2 & 1.26 & 7.02 & 1.17 & 6.98 & 0.00 & 6.55 & 0.25 & 2.05 & 0.33 & 68.03 \\
\hline 78 & & III-2-3 & 1.27 & 7.06 & 1.21 & 6.68 & 0.00 & 6.54 & 0.24 & 2.04 & 0.30 & 62.09 \\
\hline 79 & & III-3-1 & 1.25 & 7.10 & 1.25 & 8.52 & 0.01 & 9.12 & 0.17 & 1.44 & 0.45 & 64.78 \\
\hline 80 & & III-3-2 & 1.27 & 7.11 & 1.24 & 8.10 & 0.01 & 8.57 & 0.17 & 1.61 & 0.40 & 64.05 \\
\hline 81 & & III-3-3 & 1.43 & 7.14 & 1.16 & 6.98 & 0.01 & 6.61 & 0.23 & 2.08 & 0.33 & 69.02 \\
\hline
\end{tabular}


Table S1. Continued

\begin{tabular}{|c|c|c|c|c|c|c|c|c|c|c|c|c|}
\hline 82 & $0-5$ & IV-1-1 & 1.09 & 7.14 & 2.11 & 13.20 & 0.05 & 24.54 & 0.14 & 1.38 & 0.68 & 93.77 \\
\hline 83 & & IV-1-2 & 1.12 & 7.19 & 2.09 & 13.61 & 0.03 & 24.96 & 0.14 & 1.17 & 0.81 & 94.97 \\
\hline 84 & & IV-1-3 & 1.14 & 7.09 & 2.07 & 13.58 & 0.03 & 24.64 & 0.14 & 1.27 & 0.78 & 98.62 \\
\hline 85 & & IV-2-1 & 1.16 & 7.14 & 2.06 & 13.69 & 0.05 & 25.14 & 0.12 & 0.99 & 0.81 & 80.66 \\
\hline 86 & & IV-2-2 & 1.13 & 7.12 & 2.05 & 14.01 & 0.02 & 25.47 & 0.13 & 1.00 & 0.85 & 85.28 \\
\hline 87 & & IV-2-3 & 1.2 & 7.15 & 2.03 & 13.78 & 0.04 & 24.79 & 0.13 & 0.95 & 0.83 & 79.00 \\
\hline 88 & & IV-3-1 & 1.07 & 7.11 & 1.99 & 13.97 & 0.01 & 24.59 & 0.13 & 1.00 & 0.83 & 83.67 \\
\hline 89 & & IV-3-2 & 1.09 & 7.13 & 2.11 & 12.76 & 0.04 & 23.58 & 0.14 & 1.19 & 0.76 & 90.39 \\
\hline 90 & & IV-3-3 & 1.14 & 7.06 & 2.06 & 13.25 & 0.02 & 23.88 & 0.14 & 1.20 & 0.77 & 91.92 \\
\hline 91 & $5-10$ & IV-1-1 & 1.15 & 7.05 & 1.85 & 9.41 & 0.07 & 14.31 & 0.22 & 2.02 & 0.53 & 107.74 \\
\hline 92 & & IV-1-2 & 1.11 & 7.04 & 1.86 & 10.88 & 0.02 & 17.13 & 0.18 & 1.78 & 0.62 & 110.39 \\
\hline 93 & & IV-1-3 & 1.18 & 7.07 & 1.89 & 10.21 & 0.02 & 16.17 & 0.19 & 1.99 & 0.59 & 118.00 \\
\hline 94 & & IV-2-1 & 1.19 & 7.11 & 1.76 & 11.05 & 0.02 & 16.62 & 0.17 & 1.34 & 0.69 & 92.37 \\
\hline 95 & & IV-2-2 & 1.15 & 7.13 & 1.72 & 10.98 & 0.02 & 15.92 & 0.19 & 1.41 & 0.67 & 94.59 \\
\hline 96 & & IV-2-3 & 1.3 & 7.08 & 1.74 & 10.96 & 0.05 & 16.33 & 0.17 & 1.21 & 0.68 & 82.35 \\
\hline 97 & & IV-3-1 & 1.1 & 7.14 & 1.69 & 10.37 & 0.03 & 14.90 & 0.18 & 1.42 & 0.61 & 86.47 \\
\hline 98 & & IV-3-2 & 1.13 & 7.10 & 1.82 & 9.44 & 0.04 & 14.67 & 0.17 & 1.43 & 0.55 & 79.32 \\
\hline 99 & & IV-3-3 & 1.15 & 7.16 & 1.66 & 10.42 & 0.04 & 15.00 & 0.15 & 1.27 & 0.58 & 73.70 \\
\hline 100 & $10-20$ & IV-1-1 & 1.28 & 7.21 & 1.39 & 8.73 & 0.05 & 9.97 & 0.22 & 2.13 & 0.46 & 97.44 \\
\hline 101 & & IV-1-2 & 1.26 & 7.14 & 1.35 & 9.50 & 0.01 & 10.56 & 0.21 & 1.99 & 0.52 & 103.67 \\
\hline 102 & & IV-1-3 & 1.33 & 7.16 & 1.42 & 8.73 & 0.00 & 9.96 & 0.24 & 2.18 & 0.49 & 105.90 \\
\hline 103 & & IV-2-1 & 1.27 & 7.11 & 1.42 & 8.19 & 0.00 & 9.48 & 0.23 & 1.99 & 0.46 & 90.35 \\
\hline 104 & & IV-2-2 & 1.31 & 7.12 & 1.32 & 9.75 & 0.00 & 10.72 & 0.20 & 1.66 & 0.52 & 86.91 \\
\hline 105 & & IV-2-3 & 1.35 & 7.10 & 1.34 & 9.11 & 0.02 & 9.99 & 0.22 & 1.91 & 0.46 & 88.05 \\
\hline 106 & & IV-3-1 & 1.3 & 7.02 & 1.30 & 10.62 & 0.05 & 11.57 & 0.19 & 1.65 & 0.58 & 96.44 \\
\hline 107 & & IV-3-2 & 1.34 & 7.05 & 1.22 & 10.16 & 0.00 & 10.31 & 0.20 & 1.90 & 0.49 & 93.48 \\
\hline 108 & & IV-3-3 & 1.28 & 7.09 & 1.18 & 10.34 & 0.00 & 10.28 & 0.19 & 1.73 & 0.50 & 86.08 \\
\hline 109 & $0-5$ & V-1-1 & 0.91 & 7.08 & 3.40 & 15.84 & 0.29 & 47.39 & 0.14 & 1.39 & 1.32 & 182.62 \\
\hline 110 & & V-1-2 & 0.94 & 7.16 & 3.37 & 16.51 & 0.12 & 49.04 & 0.13 & 1.12 & 1.59 & 178.47 \\
\hline 111 & & V-1-3 & 0.94 & 7.12 & 3.35 & 15.87 & 0.25 & 46.81 & 0.14 & 1.22 & 1.47 & 179.67 \\
\hline 112 & & V-2-1 & 0.97 & 7.11 & 3.38 & 14.83 & 0.20 & 43.31 & 0.16 & 1.28 & 1.45 & 185.81 \\
\hline 113 & & V-2-2 & 0.99 & 7.13 & 3.41 & 14.78 & 0.18 & 43.78 & 0.15 & 1.18 & 1.50 & 177.35 \\
\hline 114 & & V-2-3 & 1.1 & 7.15 & 3.39 & 14.78 & 0.24 & 42.51 & 0.18 & 1.32 & 1.49 & 196.36 \\
\hline 115 & & V-3-1 & 0.99 & 7.11 & 3.40 & 16.56 & 0.31 & 49.33 & 0.14 & 1.09 & 1.69 & 183.36 \\
\hline 116 & & V-3-2 & 1.02 & 7.12 & 3.37 & 16.69 & 0.23 & 49.10 & 0.15 & 1.22 & 1.59 & 193.87 \\
\hline 117 & & V-3-3 & 1.03 & 7.13 & 3.43 & 15.75 & 0.19 & 47.07 & 0.15 & 1.24 & 1.52 & 188.84 \\
\hline 118 & $5-10$ & V-1-1 & 1.01 & 7.17 & 3.15 & 13.25 & 0.33 & 35.70 & 0.17 & 1.58 & 1.28 & 202.50 \\
\hline 119 & & $\mathrm{~V}-1-2$ & 1.05 & 7.15 & 3.06 & 14.14 & 0.21 & 37.25 & 0.16 & 1.58 & 1.33 & 209.68 \\
\hline 120 & & V-1-3 & 1 & 7.06 & 2.99 & 14.18 & 0.26 & 37.31 & 0.14 & 1.41 & 1.30 & 183.53 \\
\hline 121 & & $\mathrm{~V}-2-1$ & 0.99 & 7.05 & 3.18 & 12.80 & 0.29 & 34.81 & 0.17 & 1.33 & 1.45 & 192.08 \\
\hline 122 & & V-2-2 & 1.06 & 7.11 & 3.03 & 13.28 & 0.20 & 34.31 & 0.17 & 1.30 & 1.43 & 186.31 \\
\hline 123 & & V-2-3 & 1.1 & 7.08 & 3.01 & 13.39 & 0.23 & 34.35 & 0.17 & 1.26 & 1.43 & 180.37 \\
\hline
\end{tabular}


Table S1. Continued

\begin{tabular}{|c|c|c|c|c|c|c|c|c|c|c|c|c|}
\hline 124 & & V-3-1 & 1.11 & 7.16 & 3.10 & 15.47 & 0.17 & 42.68 & 0.12 & 1.00 & 1.67 & 166.19 \\
\hline 125 & & V-3-2 & 1.08 & 7.14 & 3.00 & 14.76 & 0.15 & 38.98 & 0.14 & 1.14 & 1.43 & 162.80 \\
\hline 126 & & V-3-3 & 1.13 & 7.20 & 3.08 & 14.96 & 0.21 & 40.59 & 0.14 & 1.12 & 1.54 & 172.48 \\
\hline 127 & $10-20$ & V-1-1 & 1.16 & 7.11 & 2.28 & 10.64 & 0.27 & 19.59 & 0.24 & 2.33 & 0.92 & 213.28 \\
\hline 128 & & V-1-2 & 1.18 & 7.19 & 2.22 & 12.93 & 0.15 & 24.99 & 0.15 & 1.38 & 1.16 & 160.99 \\
\hline 129 & & $\mathrm{~V}-1-3$ & 1.15 & 7.11 & 2.19 & 12.11 & 0.10 & 22.76 & 0.16 & 1.48 & 1.04 & 153.19 \\
\hline 130 & & V-2-1 & 1.13 & 7.11 & 2.02 & 14.30 & 0.11 & 24.26 & 0.19 & 1.67 & 1.13 & 188.40 \\
\hline 131 & & $\mathrm{~V}-2-2$ & 1.17 & 7.05 & 1.97 & 14.26 & 0.18 & 23.60 & 0.19 & 1.58 & 1.14 & 179.94 \\
\hline 132 & & $\mathrm{~V}-2-3$ & 1.09 & 7.07 & 2.01 & 13.43 & 0.21 & 22.32 & 0.21 & 1.80 & 1.02 & 182.76 \\
\hline 133 & & V-3-1 & 1.06 & 7.13 & 2.20 & 12.56 & 0.10 & 22.77 & 0.21 & 1.83 & 1.17 & 213.83 \\
\hline 134 & & V-3-2 & 1.19 & 7.10 & 2.14 & 11.52 & 0.08 & 19.92 & 0.24 & 2.23 & 0.98 & 217.68 \\
\hline 135 & & $V-3-3$ & 1.21 & 7.14 & 2.17 & 11.70 & 0.10 & 21.07 & 0.20 & 1.89 & 1.04 & 196.34 \\
\hline 136 & $0-5$ & VI-1-1 & 1.07 & 7.07 & 2.85 & 14.35 & 0.15 & 37.25 & 0.10 & - & - & - \\
\hline 137 & & VI-1-2 & 1.03 & 7.06 & 2.80 & 12.47 & 0.15 & 31.17 & 0.12 & - & - & - \\
\hline 138 & & VI-1-3 & 1.11 & 7.14 & 2.81 & 12.85 & 0.16 & 32.51 & 0.11 & - & - & - \\
\hline 139 & & VI-2-1 & 0.98 & 7.11 & 2.78 & 12.46 & 0.19 & 30.86 & 0.12 & - & - & - \\
\hline 140 & & VI-2-2 & 1.02 & 7.16 & 2.75 & 12.22 & 0.12 & 29.80 & 0.13 & - & - & - \\
\hline 141 & & VI-2-3 & 1.11 & 7.09 & 2.73 & 12.34 & 0.14 & 29.67 & 0.14 & - & - & - \\
\hline 142 & & VI-3-1 & 1.06 & 7.14 & 2.88 & 11.58 & 0.15 & 29.51 & 0.13 & - & - & - \\
\hline 143 & & VI-3-2 & 1.05 & 7.01 & 2.76 & 12.85 & 0.15 & 31.70 & 0.12 & - & - & - \\
\hline 144 & & VI-3-3 & 1.03 & 7.02 & 2.69 & 13.19 & 0.15 & 31.70 & 0.12 & - & - & - \\
\hline 145 & $5-10$ & VI-1-1 & 1.12 & 7.04 & 2.51 & 12.97 & 0.23 & 29.41 & 0.11 & - & - & - \\
\hline 146 & & VI-1-2 & 1.07 & 7.04 & 2.26 & 14.41 & 0.12 & 29.54 & 0.10 & - & - & - \\
\hline 147 & & VI-1-3 & 1.1 & 7.07 & 2.30 & 14.16 & 0.13 & 29.68 & 0.10 & - & - & - \\
\hline 148 & & VI-2-1 & 1.14 & 7.07 & 2.55 & 11.03 & 0.11 & 24.95 & 0.13 & - & - & - \\
\hline 149 & & VI-2-2 & 1.18 & 7.02 & 2.48 & 11.34 & 0.12 & 24.84 & 0.13 & - & - & - \\
\hline 150 & & VI-2-3 & 1.16 & 7.00 & 2.59 & 10.86 & 0.10 & 24.72 & 0.14 & - & - & - \\
\hline 151 & & VI-3-1 & 1.09 & 7.03 & 2.72 & 10.57 & 0.10 & 25.59 & 0.12 & - & - & - \\
\hline 152 & & VI-3-2 & 1.19 & 7.09 & 2.65 & 11.69 & 0.12 & 27.67 & 0.12 & - & - & - \\
\hline 153 & & VI-3-3 & 1.14 & 7.08 & 2.61 & 11.44 & 0.14 & 26.65 & 0.12 & - & - & - \\
\hline 154 & $10-20$ & VI-1-1 & 1.22 & 7.02 & 2.13 & 12.45 & 0.10 & 24.05 & 0.10 & - & - & - \\
\hline 155 & & VI-1-2 & 1.24 & 7.03 & 2.04 & 12.08 & 0.10 & 22.26 & 0.11 & - & - & - \\
\hline 156 & & VI-1-3 & 1.32 & 6.99 & 2.10 & 12.16 & 0.10 & 22.97 & 0.11 & - & - & - \\
\hline 157 & & VI-2-1 & 1.23 & 7.02 & 2.15 & 11.89 & 0.10 & 22.94 & 0.11 & - & - & - \\
\hline 158 & & VI-2-2 & 1.16 & 7.00 & 2.07 & 11.88 & 0.10 & 21.94 & 0.12 & - & - & - \\
\hline 159 & & VI-2-3 & 1.12 & 7.11 & 2.00 & 13.27 & 0.10 & 23.77 & 0.12 & - & - & - \\
\hline 160 & & VI-3-1 & 1.14 & 7.06 & 2.03 & 11.66 & 0.10 & 21.19 & 0.12 & - & - & - \\
\hline 161 & & VI-3-2 & 1.17 & 7.05 & 1.96 & 12.88 & 0.10 & 22.81 & 0.11 & - & - & - \\
\hline 162 & & VI-3-3 & 1.22 & 7.04 & 1.93 & 12.67 & 0.10 & 22.06 & 0.11 & - & - & - \\
\hline
\end{tabular}

Note: I, Zanthoxylum bungeanums; II, Hylocereus undulates III, Pennisetum sinese IV, Medicago sativa; V, Sabina chinensis; VI, abandoned and natural recovery. I-1-1, The first sample point of the first sample plot of Zanthoxylum bungeanums; I-2-1, The first sample point of the second sample plot of Zanthoxylum bungeanums. BD, Bulk density; Ph, Soil Ph; TN, Total nitrogen; C/N, Ratio of carbon and nitrogen; G, >2 mm gravel ratio; NLC, Non-labile C; L, Lability of C; LI, lability index; CPI, Carbon pool index; CPMI, Carbon Pool Management Index. 
Table S2. Soil organic carbon content and stock, and Soil labile organic carbon content.

\begin{tabular}{|c|c|c|c|c|c|c|c|c|c|c|c|c|}
\hline $\begin{array}{c}\text { Serial } \\
\text { number }\end{array}$ & $\begin{array}{c}\text { Soil } \\
\text { layer }\end{array}$ & $\begin{array}{c}\text { No. of } \\
\text { sample } \\
\text { plot }\end{array}$ & $\begin{array}{c}\mathrm{SOC} \\
(\mathrm{g} / \mathrm{kg})\end{array}$ & $\begin{array}{c}\text { SOCS } \\
\left(\mathrm{kg} / \mathrm{m}^{2}\right)\end{array}$ & $\begin{array}{l}\text { WSOC } \\
(\mathrm{mg} / \mathrm{kg})\end{array}$ & $\begin{array}{c}\text { EOC } \\
(\mathrm{g} / \mathrm{kg})\end{array}$ & $\begin{array}{c}\mathrm{POC} \\
(\mathrm{g} / \mathrm{kg})\end{array}$ & $\begin{array}{l}\text { LFOC } \\
(\mathrm{g} / \mathrm{kg})\end{array}$ & $\begin{array}{c}\text { WSOC/SOC } \\
(\%)\end{array}$ & $\begin{array}{c}\text { EOC/SOC } \\
(\%)\end{array}$ & $\begin{array}{c}\mathrm{POC} / \mathrm{SOC} \\
(\%)\end{array}$ & $\begin{array}{c}\mathrm{LFOC} / \mathrm{SOC} \\
(\%)\end{array}$ \\
\hline 1 & $0-5$ & I-1-1 & 30.33 & 1.37 & 88.63 & 3.26 & 3.85 & 1.26 & 0.29 & 10.75 & 12.69 & 4.15 \\
\hline 2 & & $\mathrm{I}-1-2$ & 28.76 & 1.30 & 96.51 & 3.61 & 3.92 & 1.17 & 0.34 & 12.55 & 13.63 & 4.07 \\
\hline 3 & & $\mathrm{I}-1-3$ & 29.58 & 1.32 & 91.00 & 3.62 & 3.81 & 1.35 & 0.31 & 12.23 & 12.87 & 4.57 \\
\hline 4 & & I-2-1 & 26.34 & 1.26 & 103.14 & 3.34 & 3.88 & 1.09 & 0.39 & 12.67 & 14.73 & 4.14 \\
\hline 5 & & I-2-2 & 27.82 & 1.31 & 116.27 & 3.36 & 3.96 & 1.02 & 0.42 & 12.08 & 14.23 & 3.67 \\
\hline 6 & & $\mathrm{I}-2-3$ & 26.93 & 1.43 & 128.40 & 3.77 & 4.19 & 0.82 & 0.48 & 14.01 & 15.54 & 3.04 \\
\hline 7 & & I-3-1 & 33.19 & 1.61 & 89.66 & 3.51 & 3.94 & 1.15 & 0.27 & 10.58 & 11.87 & 3.46 \\
\hline 8 & & I-3-2 & 32.29 & 1.63 & 97.53 & 3.46 & 3.97 & 1.21 & 0.30 & 10.72 & 12.29 & 3.75 \\
\hline 9 & & I-3-3 & 32.67 & 1.50 & 84.00 & 3.93 & 3.91 & 1.24 & 0.26 & 12.03 & 11.98 & 3.81 \\
\hline 10 & $5-10$ & I-1-1 & 19.14 & 0.88 & 78.65 & 2.97 & 2.83 & 0.63 & 0.41 & 15.52 & 14.79 & 3.29 \\
\hline 11 & & I-1-2 & 19.36 & 0.95 & 72.01 & 3.04 & 2.79 & 0.66 & 0.37 & 15.70 & 14.41 & 3.41 \\
\hline 12 & & I-1-3 & 19.21 & 0.96 & 68.70 & 3.40 & 2.75 & 0.66 & 0.36 & 17.69 & 14.31 & 3.45 \\
\hline 13 & & I-2-1 & 22.51 & 1.22 & 85.36 & 3.10 & 2.85 & 0.72 & 0.38 & 13.77 & 12.66 & 3.20 \\
\hline 14 & & I-2-2 & 21.60 & 1.16 & 89.77 & 3.15 & 2.92 & 0.61 & 0.42 & 14.58 & 13.52 & 2.82 \\
\hline 15 & & I-2-3 & 22.12 & 1.29 & 102.70 & 3.29 & 2.99 & 0.77 & 0.46 & 14.87 & 13.54 & 3.47 \\
\hline 16 & & I-3-1 & 20.39 & 1.02 & 71.24 & 3.06 & 2.99 & 0.75 & 0.35 & 15.01 & 14.66 & 3.68 \\
\hline 17 & & $\mathrm{I}-3-2$ & 20.52 & 1.04 & 73.68 & 2.87 & 3.04 & 0.59 & 0.36 & 13.99 & 14.81 & 2.88 \\
\hline 18 & & I-3-3 & 20.59 & 1.03 & 69.00 & 3.51 & 3.06 & 0.62 & 0.34 & 17.06 & 14.89 & 2.99 \\
\hline 19 & $10-20$ & I-1-1 & 14.28 & 0.82 & 65.47 & 2.77 & 1.63 & 0.52 & 0.46 & 19.40 & 11.41 & 3.64 \\
\hline 20 & & I-1-2 & 16.33 & 0.92 & 63.65 & 2.72 & 1.72 & 0.41 & 0.39 & 16.66 & 10.53 & 2.51 \\
\hline 21 & & I-1-3 & 15.25 & 0.91 & 63.10 & 3.12 & 1.58 & 0.45 & 0.41 & 20.47 & 10.36 & 2.98 \\
\hline 22 & & I-2-1 & 15.55 & 0.92 & 72.21 & 2.81 & 2.01 & 0.41 & 0.46 & 18.07 & 12.93 & 2.64 \\
\hline 23 & & I-2-2 & 17.30 & 1.05 & 71.50 & 2.63 & 1.99 & 0.48 & 0.41 & 15.20 & 11.50 & 2.77 \\
\hline 24 & & I-2-3 & 16.31 & 1.12 & 85.40 & 2.65 & 2.11 & 0.53 & 0.52 & 16.26 & 12.91 & 3.28 \\
\hline 25 & & I-3-1 & 15.44 & 0.90 & 58.39 & 2.69 & 1.95 & 0.53 & 0.38 & 17.42 & 12.63 & 3.43 \\
\hline 26 & & $\mathrm{I}-3-2$ & 17.69 & 1.05 & 61.07 & 2.74 & 1.97 & 0.48 & 0.35 & 15.49 & 11.14 & 2.71 \\
\hline 27 & & I-3-3 & 16.52 & 1.05 & 56.00 & 3.04 & 2.10 & 0.51 & 0.34 & 18.40 & 12.71 & 3.12 \\
\hline 28 & $0-5$ & II-1-1 & 20.70 & 1.03 & 88.62 & 2.91 & 2.64 & 1.46 & 0.43 & 14.06 & 12.75 & 7.05 \\
\hline 29 & & II-1-2 & 22.03 & 1.15 & 91.36 & 2.83 & 2.71 & 1.52 & 0.41 & 12.85 & 12.30 & 6.90 \\
\hline 30 & & II-1-3 & 21.77 & 1.21 & 93.60 & 2.98 & 2.59 & 1.54 & 0.43 & 13.69 & 11.92 & 7.09 \\
\hline 31 & & II-2-1 & 21.24 & 1.19 & 85.46 & 2.70 & 2.75 & 1.51 & 0.40 & 12.71 & 12.95 & 7.11 \\
\hline 32 & & II-2-2 & 22.44 & 1.24 & 88.13 & 2.72 & 2.73 & 1.36 & 0.39 & 12.12 & 12.17 & 6.06 \\
\hline 33 & & II-2-3 & 21.75 & 1.36 & 87.30 & 2.76 & 2.85 & 1.63 & 0.40 & 12.69 & 13.10 & 7.49 \\
\hline 34 & & II-3-1 & 19.70 & 1.10 & 76.58 & 2.84 & 2.88 & 1.22 & 0.39 & 14.40 & 14.62 & 6.19 \\
\hline 35 & & II-3-2 & 20.28 & 1.18 & 81.64 & 2.71 & 2.82 & 1.27 & 0.40 & 13.36 & 13.91 & 6.26 \\
\hline 36 & & II-3-3 & 18.49 & 0.87 & 84.00 & 2.87 & 2.98 & 1.26 & 0.45 & 15.51 & 16.13 & 6.83 \\
\hline 37 & $5-10$ & II-1-1 & 15.44 & 0.87 & 77.32 & 2.43 & 1.84 & 0.61 & 0.50 & 15.74 & 11.92 & 3.95 \\
\hline 38 & & II-1-2 & 14.32 & 0.76 & 76.51 & 2.39 & 1.76 & 0.65 & 0.53 & 16.69 & 12.29 & 4.54 \\
\hline 39 & & II-1-3 & 14.67 & 0.85 & 75.60 & 2.54 & 2.04 & 0.63 & 0.52 & 17.29 & 13.92 & 4.33 \\
\hline 40 & & II-2-1 & 17.23 & 0.95 & 67.83 & 2.18 & 1.83 & 0.61 & 0.39 & 12.65 & 10.62 & 3.54 \\
\hline
\end{tabular}


Table S2. Continued

\begin{tabular}{|c|c|c|c|c|c|c|c|c|c|c|c|c|}
\hline 41 & & II-2-2 & 16.55 & 0.96 & 73.86 & 2.31 & 1.85 & 0.73 & 0.45 & 13.96 & 11.18 & 4.41 \\
\hline 42 & & II-2-3 & 15.39 & 1.03 & 70.60 & 2.06 & 1.80 & 0.67 & 0.46 & 13.39 & 11.68 & 4.35 \\
\hline 43 & & II-3-1 & 12.12 & 0.70 & 68.75 & 2.46 & 1.82 & 0.58 & 0.57 & 20.30 & 15.02 & 4.79 \\
\hline 44 & & II-3-2 & 12.39 & 0.71 & 71.29 & 2.52 & 1.88 & 0.79 & 0.58 & 20.34 & 15.17 & 6.38 \\
\hline 45 & & II-3-3 & 13.76 & 0.81 & 72.50 & 2.57 & 1.78 & 0.73 & 0.53 & 18.69 & 12.96 & 5.27 \\
\hline 46 & $10-20$ & II-1-1 & 10.59 & 0.62 & 63.42 & 1.88 & 1.15 & 0.42 & 0.60 & 17.75 & 10.86 & 3.97 \\
\hline 47 & & II-1-2 & 10.33 & 0.62 & 60.56 & 2.01 & 1.20 & 0.39 & 0.59 & 19.46 & 11.62 & 3.78 \\
\hline 48 & & II-1-3 & 10.55 & 0.64 & 65.20 & 2.03 & 1.28 & 0.40 & 0.62 & 19.28 & 12.10 & 3.76 \\
\hline 49 & & II-2-1 & 10.65 & 0.66 & 55.96 & 1.75 & 1.24 & 0.41 & 0.53 & 16.43 & 11.64 & 3.85 \\
\hline 50 & & II-2-2 & 10.92 & 0.69 & 64.31 & 1.89 & 1.36 & 0.44 & 0.59 & 17.31 & 12.45 & 4.03 \\
\hline 51 & & II-2-3 & 10.86 & 0.76 & 57.90 & 1.67 & 1.28 & 0.45 & 0.53 & 15.39 & 11.78 & 4.18 \\
\hline 52 & & II-3-1 & 8.32 & 0.52 & 51.12 & 1.76 & 1.17 & 0.36 & 0.61 & 21.15 & 14.06 & 4.33 \\
\hline 53 & & II-3-2 & 9.39 & 0.57 & 59.77 & 1.74 & 1.04 & 0.45 & 0.64 & 18.53 & 11.08 & 4.79 \\
\hline 54 & & II-3-3 & 8.56 & 0.56 & 56.70 & 1.73 & 1.10 & 0.38 & 0.66 & 20.20 & 12.81 & 4.46 \\
\hline 55 & $0-5$ & III-1-1 & 23.14 & 1.22 & 88.76 & 2.99 & 2.65 & 1.52 & 0.38 & 12.92 & 11.45 & 6.57 \\
\hline 56 & & III-1-2 & 24.66 & 1.28 & 82.49 & 2.86 & 2.77 & 1.43 & 0.33 & 11.60 & 11.23 & 5.80 \\
\hline 57 & & III-1-3 & 23.81 & 1.43 & 106.60 & 3.23 & 2.60 & 1.58 & 0.45 & 13.55 & 10.92 & 6.65 \\
\hline 58 & & III-2-1 & 18.75 & 1.02 & 91.62 & 2.62 & 2.81 & 1.39 & 0.49 & 13.97 & 14.99 & 7.41 \\
\hline 59 & & III-2-2 & 18.70 & 0.99 & 86.47 & 2.71 & 2.86 & 1.31 & 0.46 & 14.49 & 15.29 & 7.01 \\
\hline 60 & & III-2-3 & 17.23 & 0.98 & 82.30 & 2.79 & 2.95 & 1.32 & 0.48 & 16.17 & 17.14 & 7.66 \\
\hline 61 & & III-3-1 & 20.55 & 1.11 & 81.33 & 2.84 & 2.93 & 1.20 & 0.40 & 13.82 & 14.26 & 5.84 \\
\hline 62 & & III-3-2 & 20.81 & 1.16 & 80.40 & 2.73 & 2.89 & 1.35 & 0.39 & 13.12 & 13.89 & 6.49 \\
\hline 63 & & III-3-3 & 20.76 & 1.15 & 80.20 & 2.56 & 3.07 & 1.48 & 0.39 & 12.32 & 14.78 & 7.13 \\
\hline 64 & $5-10$ & III-1-1 & 17.44 & 1.03 & 76.41 & 2.26 & 1.85 & 0.74 & 0.44 & 12.96 & 10.61 & 4.24 \\
\hline 65 & & III-1-2 & 13.39 & 0.83 & 71.26 & 2.01 & 1.92 & 0.73 & 0.53 & 15.01 & 14.34 & 5.45 \\
\hline 66 & & III-1-3 & 13.92 & 0.84 & 82.10 & 2.23 & 1.99 & 0.81 & 0.59 & 16.00 & 14.32 & 5.84 \\
\hline 67 & & III-2-1 & 15.60 & 0.95 & 77.48 & 2.06 & 1.77 & 0.62 & 0.50 & 13.21 & 11.35 & 3.97 \\
\hline 68 & & III-2-2 & 13.75 & 0.84 & 76.53 & 2.17 & 1.89 & 0.66 & 0.56 & 15.78 & 13.75 & 4.80 \\
\hline 69 & & III-2-3 & 14.60 & 0.97 & 63.40 & 2.10 & 1.74 & 0.57 & 0.43 & 14.35 & 11.95 & 3.88 \\
\hline 70 & & III-3-1 & 13.70 & 0.86 & 71.95 & 2.21 & 2.06 & 0.63 & 0.53 & 16.13 & 15.04 & 4.60 \\
\hline 71 & & III-3-2 & 14.20 & 0.84 & 74.52 & 2.14 & 1.83 & 0.60 & 0.52 & 15.07 & 12.89 & 4.23 \\
\hline 72 & & III-3-3 & 13.20 & 0.83 & 70.60 & 1.89 & 2.37 & 0.63 & 0.53 & 14.34 & 17.94 & 4.77 \\
\hline 73 & $10-20$ & III-1-1 & 8.96 & 0.55 & 61.42 & 1.63 & 1.17 & 0.37 & 0.69 & 18.19 & 13.06 & 4.13 \\
\hline 74 & & III-1-2 & 9.65 & 0.62 & 62.53 & 1.59 & 1.21 & 0.34 & 0.65 & 16.48 & 12.54 & 3.52 \\
\hline 75 & & III-1-3 & 9.23 & 0.60 & 75.50 & 1.66 & 1.26 & 0.34 & 0.82 & 17.94 & 13.69 & 3.72 \\
\hline 76 & & III-2-1 & 7.79 & 0.50 & 66.79 & 1.51 & 1.23 & 0.31 & 0.86 & 19.38 & 15.79 & 3.98 \\
\hline 77 & & III-2-2 & 8.17 & 0.51 & 68.25 & 1.62 & 1.14 & 0.29 & 0.84 & 19.83 & 13.95 & 3.55 \\
\hline 78 & & III-2-3 & 8.09 & 0.51 & 63.40 & 1.55 & 1.05 & 0.33 & 0.78 & 19.16 & 13.02 & 4.12 \\
\hline 79 & & III-3-1 & 10.65 & 0.66 & 61.34 & 1.53 & 1.02 & 0.42 & 0.58 & 14.37 & 9.58 & 3.94 \\
\hline 80 & & III-3-2 & 10.04 & 0.63 & 62.10 & 1.47 & 1.13 & 0.33 & 0.62 & 14.64 & 11.25 & 3.29 \\
\hline 81 & & III-3-3 & 8.10 & 0.57 & 65.90 & 1.49 & 1.07 & 0.36 & 0.81 & 18.42 & 13.26 & 4.43 \\
\hline 82 & $0-5$ & IV-1-1 & 27.86 & 1.44 & 86.19 & 3.32 & 2.99 & 0.96 & 0.31 & 11.92 & 10.73 & 3.45 \\
\hline
\end{tabular}


Table S2. Continued

\begin{tabular}{|c|c|c|c|c|c|c|c|c|c|c|c|c|}
\hline 83 & & IV-1-2 & 28.45 & 1.55 & 82.94 & 3.49 & 3.05 & 0.87 & 0.29 & 12.27 & 10.72 & 3.06 \\
\hline 84 & & IV-1-3 & 28.10 & 1.55 & 82.00 & 3.46 & 3.08 & 0.92 & 0.29 & 12.32 & 10.97 & 3.27 \\
\hline 85 & & IV-2-1 & 28.20 & 1.55 & 91.31 & 3.06 & 3.21 & 0.91 & 0.32 & 10.85 & 11.38 & 3.23 \\
\hline 86 & & IV-2-2 & 28.72 & 1.59 & 85.73 & 3.25 & 3.36 & 0.88 & 0.30 & 11.32 & 11.70 & 3.06 \\
\hline 87 & & IV-2-3 & 27.98 & 1.61 & 94.20 & 3.19 & 3.41 & 0.93 & 0.34 & 11.39 & 12.19 & 3.33 \\
\hline 88 & & IV-3-1 & 27.81 & 1.47 & 88.19 & 3.22 & 3.27 & 0.86 & 0.32 & 11.58 & 11.76 & 3.09 \\
\hline 89 & & IV-3-2 & 26.92 & 1.41 & 87.00 & 3.34 & 3.55 & 0.95 & 0.32 & 12.41 & 13.19 & 3.53 \\
\hline 90 & & IV-3-3 & 27.29 & 1.52 & 91.10 & 3.41 & 3.71 & 0.85 & 0.33 & 12.48 & 13.60 & 3.13 \\
\hline 91 & $5-10$ & IV-1-1 & 17.40 & 0.93 & 76.59 & 3.09 & 2.45 & 0.71 & 0.44 & 17.76 & 14.08 & 4.08 \\
\hline 92 & & IV-1-2 & 20.24 & 1.10 & 82.48 & 3.11 & 2.41 & 0.75 & 0.41 & 15.37 & 11.91 & 3.71 \\
\hline 93 & & IV-1-3 & 19.30 & 1.12 & 77.30 & 3.13 & 2.34 & 1.04 & 0.40 & 16.20 & 12.14 & 5.37 \\
\hline 94 & & IV-2-1 & 19.45 & 1.13 & 80.62 & 2.83 & 2.47 & 0.80 & 0.41 & 14.55 & 12.70 & 4.11 \\
\hline 95 & & IV-2-2 & 18.89 & 1.06 & 88.73 & 2.97 & 2.52 & 0.74 & 0.47 & 15.72 & 13.34 & 3.92 \\
\hline 96 & & IV-2-3 & 19.07 & 1.18 & 81.40 & 2.74 & 2.71 & 1.01 & 0.43 & 14.35 & 14.22 & 5.28 \\
\hline 97 & & IV-3-1 & 17.52 & 0.93 & 87.14 & 2.62 & 2.53 & 0.76 & 0.50 & 14.95 & 14.44 & 4.34 \\
\hline 98 & & IV-3-2 & 17.18 & 0.93 & 79.64 & 2.51 & 2.49 & 0.73 & 0.46 & 14.61 & 14.49 & 4.25 \\
\hline 99 & & IV-3-3 & 17.31 & 0.96 & 77.10 & 2.31 & 2.61 & 0.78 & 0.45 & 13.33 & 15.07 & 4.49 \\
\hline 100 & $10-20$ & IV-1-1 & 12.14 & 0.74 & 66.36 & 2.17 & 2.15 & 0.62 & 0.55 & 17.87 & 17.71 & 5.11 \\
\hline 101 & & IV-1-2 & 12.82 & 0.80 & 71.45 & 2.26 & 2.18 & 0.55 & 0.56 & 17.63 & 17.00 & 4.29 \\
\hline 102 & & IV-1-3 & 12.39 & 0.82 & 69.80 & 2.43 & 2.28 & 0.97 & 0.56 & 19.60 & 18.40 & 7.86 \\
\hline 103 & & IV-2-1 & 11.63 & 0.74 & 79.71 & 2.15 & 2.09 & 0.61 & 0.69 & 18.49 & 17.97 & 5.25 \\
\hline 104 & & IV-2-2 & 12.87 & 0.84 & 75.36 & 2.15 & 2.17 & 0.60 & 0.59 & 16.71 & 16.86 & 4.66 \\
\hline 105 & & IV-2-3 & 12.21 & 0.81 & 80.10 & 2.22 & 2.17 & 0.68 & 0.66 & 18.20 & 17.81 & 5.60 \\
\hline 106 & & IV-3-1 & 13.80 & 0.85 & 80.21 & 2.23 & 2.16 & 0.52 & 0.58 & 16.16 & 15.65 & 3.77 \\
\hline 107 & & IV-3-2 & 12.40 & 0.83 & 77.51 & 2.09 & 2.22 & 0.53 & 0.63 & 16.85 & 17.90 & 4.27 \\
\hline 108 & & IV-3-3 & 12.20 & 0.78 & 72.40 & 1.92 & 2.24 & 0.50 & 0.59 & 15.75 & 18.40 & 4.12 \\
\hline 109 & $0-5$ & V-1-1 & 53.85 & 1.74 & 188.31 & 6.46 & 23.61 & 5.06 & 0.35 & 12.00 & 43.84 & 9.40 \\
\hline 110 & & V-1-2 & 55.63 & 2.30 & 194.92 & 6.59 & 24.52 & 5.17 & 0.35 & 11.85 & 44.08 & 9.29 \\
\hline 111 & & V-1-3 & 53.15 & 1.87 & 218.70 & 6.34 & 25.52 & 4.66 & 0.41 & 11.92 & 48.01 & 8.78 \\
\hline 112 & & V-2-1 & 50.14 & 1.95 & 174.42 & 6.83 & 22.91 & 5.65 & 0.35 & 13.62 & 45.69 & 11.27 \\
\hline 113 & & $\mathrm{~V}-2-2$ & 50.40 & 2.05 & 163.81 & 6.62 & 21.82 & 5.39 & 0.33 & 13.13 & 43.29 & 10.69 \\
\hline 114 & & $\mathrm{~V}-2-3$ & 50.09 & 2.09 & 119.70 & 7.58 & 23.96 & 6.22 & 0.24 & 15.14 & 47.83 & 12.42 \\
\hline 115 & & V-3-1 & 56.32 & 1.92 & 172.35 & 6.99 & 21.74 & 5.83 & 0.31 & 12.41 & 38.60 & 10.35 \\
\hline 116 & & V-3-2 & 56.24 & 2.21 & 180.83 & 7.14 & 21.89 & 6.11 & 0.32 & 12.70 & 38.92 & 10.86 \\
\hline 117 & & V-3-3 & 54.03 & 2.25 & 209.60 & 6.96 & 21.66 & 6.77 & 0.39 & 12.89 & 40.09 & 12.53 \\
\hline 118 & $5-10$ & V-1-1 & 41.74 & 1.41 & 163.24 & 6.04 & 19.66 & 3.01 & 0.39 & 14.47 & 47.10 & 7.21 \\
\hline 119 & & $\mathrm{~V}-1-2$ & 43.26 & 1.79 & 158.42 & 6.01 & 20.05 & 2.98 & 0.37 & 13.89 & 46.35 & 6.89 \\
\hline 120 & & V-1-3 & 42.41 & 1.57 & 172.90 & 5.10 & 19.52 & 3.08 & 0.41 & 12.03 & 46.03 & 7.27 \\
\hline 121 & & V-2-1 & 40.70 & 1.43 & 163.24 & 5.89 & 18.57 & 3.02 & 0.40 & 14.47 & 45.63 & 7.42 \\
\hline 122 & & $\mathrm{~V}-2-2$ & 40.23 & 1.71 & 147.89 & 5.92 & 18.64 & 3.16 & 0.37 & 14.72 & 46.33 & 7.85 \\
\hline 123 & & V-2-3 & 40.32 & 1.71 & 133.20 & 5.96 & 17.09 & 3.05 & 0.33 & 14.79 & 42.38 & 7.58 \\
\hline 124 & & V-3-1 & 47.95 & 2.21 & 162.98 & 5.27 & 19.18 & 3.21 & 0.34 & 10.99 & 40.00 & 6.69 \\
\hline
\end{tabular}


Table S2. Continued

\begin{tabular}{|c|c|c|c|c|c|c|c|c|c|c|c|c|}
\hline 125 & & $\mathrm{~V}-3-2$ & 44.29 & 2.03 & 177.31 & 5.31 & 21.35 & 3.16 & 0.40 & 11.99 & 48.21 & 7.13 \\
\hline 126 & & $V-3-3$ & 46.08 & 2.06 & 181.80 & 5.49 & 20.12 & 3.37 & 0.39 & 11.91 & 43.67 & 7.31 \\
\hline 127 & $10-20$ & V-1-1 & 24.26 & 1.03 & 126.42 & 4.67 & 6.02 & 1.45 & 0.52 & 19.25 & 24.81 & 5.98 \\
\hline 128 & & V-1-2 & 28.70 & 1.44 & 163.10 & 3.71 & 6.11 & 1.51 & 0.57 & 12.93 & 21.29 & 5.26 \\
\hline 129 & & V-1-3 & 26.51 & 1.37 & 180.50 & 3.75 & 6.13 & 1.43 & 0.68 & 14.15 & 23.12 & 5.39 \\
\hline 130 & & V-2-1 & 28.88 & 1.45 & 96.41 & 4.62 & 6.17 & 1.63 & 0.33 & 16.00 & 21.36 & 5.64 \\
\hline 131 & & $\mathrm{~V}-2-2$ & 28.09 & 1.35 & 107.49 & 4.49 & 6.21 & 1.60 & 0.38 & 15.98 & 22.11 & 5.70 \\
\hline 132 & & $\mathrm{~V}-2-3$ & 26.99 & 1.16 & 92.40 & 4.66 & 6.40 & 1.84 & 0.34 & 17.29 & 23.72 & 6.80 \\
\hline 133 & & V-3-1 & 27.63 & 1.32 & 103.67 & 4.86 & 6.15 & 2.15 & 0.38 & 17.59 & 22.26 & 7.78 \\
\hline 134 & & $\mathrm{~V}-3-2$ & 24.65 & 1.35 & 124.83 & 4.73 & 6.28 & 2.37 & 0.51 & 19.19 & 25.48 & 9.61 \\
\hline 135 & & $V-3-3$ & 25.39 & 1.38 & 184.40 & 4.32 & 6.11 & 2.69 & 0.73 & 17.01 & 24.06 & 10.60 \\
\hline 136 & $0-5$ & VI-1-1 & 40.91 & 1.86 & 132.19 & 3.66 & 12.19 & 1.71 & 0.32 & 8.95 & 29.80 & 4.18 \\
\hline 137 & & VI-1-2 & 34.91 & 1.53 & 133.44 & 3.74 & 11.38 & 1.68 & 0.38 & 10.71 & 32.60 & 4.81 \\
\hline 138 & & VI-1-3 & 36.11 & 1.68 & 127.40 & 3.60 & 13.31 & 1.75 & 0.35 & 9.98 & 36.86 & 4.85 \\
\hline 139 & & VI-2-1 & 34.65 & 1.38 & 112.37 & 3.79 & 12.85 & 1.65 & 0.32 & 10.94 & 37.09 & 4.76 \\
\hline 140 & & VI-2-2 & 33.61 & 1.51 & 119.00 & 3.81 & 10.19 & 1.78 & 0.35 & 11.34 & 30.32 & 5.30 \\
\hline 141 & & VI-2-3 & 33.68 & 1.61 & 107.00 & 4.01 & 9.98 & 1.72 & 0.32 & 11.90 & 29.64 & 5.10 \\
\hline 142 & & VI-3-1 & 33.36 & 1.50 & 124.15 & 3.85 & 11.08 & 1.62 & 0.37 & 11.54 & 33.21 & 4.86 \\
\hline 143 & & VI-3-2 & 35.47 & 1.58 & 136.96 & 3.77 & 12.33 & 1.64 & 0.39 & 10.63 & 34.76 & 4.62 \\
\hline 144 & & VI-3-3 & 35.48 & 1.55 & 154.40 & 3.78 & 11.88 & 1.58 & 0.44 & 10.66 & 33.50 & 4.46 \\
\hline 145 & $5-10$ & VI-1-1 & 32.56 & 1.40 & 88.65 & 3.15 & 9.73 & 1.37 & 0.27 & 9.67 & 29.88 & 4.21 \\
\hline 146 & & VI-1-2 & 32.56 & 1.53 & 89.71 & 3.02 & 9.92 & 1.35 & 0.28 & 9.28 & 30.47 & 4.15 \\
\hline 147 & & VI-1-3 & 32.56 & 1.56 & 70.60 & 2.88 & 10.59 & 1.41 & 0.22 & 8.85 & 32.51 & 4.33 \\
\hline 148 & & VI-2-1 & 28.13 & 1.43 & 96.13 & 3.18 & 9.61 & 1.21 & 0.34 & 11.30 & 34.16 & 4.30 \\
\hline 149 & & VI-2-2 & 28.13 & 1.46 & 92.65 & 3.29 & 9.91 & 1.30 & 0.33 & 11.70 & 35.23 & 4.62 \\
\hline 150 & & VI-2-3 & 28.13 & 1.47 & 105.60 & 3.41 & 9.50 & 1.23 & 0.38 & 12.12 & 33.78 & 4.38 \\
\hline 151 & & VI-3-1 & 28.76 & 1.41 & 101.37 & 3.17 & 9.90 & 1.16 & 0.35 & 11.02 & 34.42 & 4.03 \\
\hline 152 & & VI-3-2 & 30.98 & 1.62 & 96.21 & 3.31 & 10.14 & 1.28 & 0.31 & 10.68 & 32.73 & 4.13 \\
\hline 153 & & VI-3-3 & 29.87 & 1.46 & 126.50 & 3.22 & 9.93 & 1.17 & 0.42 & 10.79 & 33.23 & 3.92 \\
\hline 154 & $10-20$ & VI-1-1 & 26.51 & 1.46 & 79.18 & 2.46 & 7.56 & 0.96 & 0.30 & 9.28 & 28.52 & 3.62 \\
\hline 155 & & VI-1-2 & 24.65 & 1.38 & 72.05 & 2.39 & 7.48 & 1.05 & 0.29 & 9.70 & 30.34 & 4.26 \\
\hline 156 & & VI-1-3 & 25.54 & 1.52 & 77.80 & 2.57 & 7.36 & 1.02 & 0.30 & 10.05 & 28.83 & 4.01 \\
\hline 157 & & VI-2-1 & 25.56 & 1.41 & 82.63 & 2.62 & 8.21 & 1.04 & 0.32 & 10.25 & 32.12 & 4.07 \\
\hline 158 & & VI-2-2 & 24.59 & 1.28 & 80.09 & 2.65 & 8.10 & 1.11 & 0.33 & 10.78 & 32.94 & 4.51 \\
\hline 159 & & VI-2-3 & 26.53 & 1.34 & 98.90 & 2.76 & 7.64 & 0.99 & 0.37 & 10.42 & 28.81 & 3.74 \\
\hline 160 & & VI-3-1 & 23.66 & 1.21 & 91.24 & 2.47 & 7.36 & 1.03 & 0.39 & 10.44 & 31.11 & 4.35 \\
\hline 161 & & VI-3-2 & 25.24 & 1.33 & 73.31 & 2.43 & 7.25 & 0.85 & 0.29 & 9.63 & 28.72 & 3.37 \\
\hline 162 & & VI-3-3 & 24.45 & 1.34 & 112.00 & 2.39 & 7.93 & 1.00 & 0.46 & 9.78 & 32.42 & 4.07 \\
\hline
\end{tabular}

Note: SOC, Soil organic carbon content; SOCS, Soil organic carbon stock; WSOC, water-soluble organic carbon; EOC, easily oxidizable organic carbon; POC, particulate organic carbon; LFOC, light fraction organic carbon; WSOC/SOC, Ratio of WSOC to SOC; EOC/SOC, Ratio of EOC to SOC; POC/SOC, Ratio of POC to SOC; LFOC/SOC, Ratio of LFOC to SOC. 